The final version of this revised manuscript has been published as:

Modulators of calpain activity: inhibitors and activators as potential drugs

Levente Endre Dókus, Mo’ath Yousef \& Zoltán Bánóczi

Pharmaceutics 2020, 15(4), 471-486

DOI: $10.1080 / 17460441.2020 .1722638$

https://doi.org/10.1080/17460441.2020.1722638

CC BY-NC-ND 


\title{
Modulators of calpain activity: inhibitors and activators as potential drugs
}

\begin{abstract}
Introduction Calpains are intracellular $\mathrm{Ca}^{2+}$-dependent cysteine proteases with 15 known members in the enzyme family. They act as regulatory enzymes, their cleavage modifies the function of their substrates. As their substrates have important roles in many physiological processes, adequate function of calpains is mandatory for normal cellular functions. Adverse operation of them is often related with diseases (e.g. neurodegenerative disorders, cancer, type 2 diabetes mellitus or limb-girdle muscular dystrophy type 2A).

Areas covered Herein, the authors give an overview about calpains, their structure, physiological and pathological functions. The challenges in the drug discovery of calpain inhibitors and activators are enlightened by summarising examples that eventuated good candidates. Going through these examples new and applicable strategies are discussed.

Expert opinion Calpain enzymes are attractive targets to design inhibitors or activators for drug development. This research area has high potential, although it has many challenges. The selective and targeted inhibition or activation of calpains is needed. Thus the studies focused on the improvement of these properties of drug candidates.
\end{abstract}

Keywordscalpain, cysteine proteases, calpastatin, calpain inhibitor, calpain activator, structure-activity-relationship (SAR)

Article highlights

- Calpains are intracellular cysteine proteases with very diverse physiological roles.

- Aberrant activity of them; over- or under activation; is often involved in pathological functions and thus in disease.

- Specific and effective inhibitors may be potent candidate to treat these diseases.

- Peptide and peptidomimetic inhibitors were developed to increase the specificity and potency using different strategies. 
- Activators can be used in treatment of diseases with low calpain activity.

- In case of both inhibitors and activators, targeted activity and high selectivity are desired.

\section{Introduction}

In 1964 a new neutral $\mathrm{Ca}^{2+}$ ion activated proteinase was described [1]. That was only the first member of an enzyme family that was first called Ca-activated neutral proteases. When $\mathrm{Ca}^{2+}$ ion concentration requirement was determined, the first identified two members were named as $\mu$ - and m-calpain [2,3]. Calpains are intracellular enzymes and modulate the function of their substrate proteins by limited proteolysis. This regulatory effect plays crucial roles in several cellular processes. Hence their activation and inactivation are under tight control. Disturbance in their normal action, increased or decreased activity, is involved in the development of pathological symptoms and has important role in many diseases. This makes them promising therapeutic targets, although there are several challenges in the drug design of calpain inhibitors or activators. In this review the calpain enzyme family, their structure and physiological functions are described. The pathological malfunctions, caused by the altered calpain activity, are highlighted to demonstrate the potency of these enzymes as targets for drug development. After historical introduction of calpain inhibitors, the strategies of development of inhibitors or activators are in the focus. We also place emphasis on the dual behaviour of calpains; as both over- and under activation may cause alteration in physiological functions.

\section{The Calpain family}

\subsection{Structure of calpains}

Calpain enzymes are intracellular $\mathrm{Ca}^{2+}$ ion activated neutral cysteine proteases (Clan CA, family C02, EC 3.4.22.17) [4]. The first two described members of this family were the 
calpain 1 and 2 [4]. These proteases, called conventional calpains, are ubiquitous and wellstudied members. Their activation needs micro- and millimolar concentration of $\mathrm{Ca}^{2+}$ ion in vitro respectively [5]. They were called $\mu$ - and m-calpain based on this sensitivity for $\mathrm{Ca}^{2+}$ ion. Both enzymes form heterodimers with a small regulatory subunit (calpain 4), and expressed in all tissues, while many of the later described members have tissue specific distribution (calpain 3, 6, 8, 9 11, 12, 15 and 16) [6] (Table 1). There are 15 calpain genes in the human genome (CAPN1 to CAPN16, no CAPN4). Calpains are classified as classical or non-classical calpains based on their domain structure; on what kind of conserved protein domains are attached to the well-conserved cysteine protease domain (CysPc) (Fig. 1A) [7]. The CysPc domain in calpain is composed of protease core 1 (PC1) and PC2 domains. Amino acids that form the catalytic triad were in distinct domains; the Cys is in the PC1 while the His and Asn are in the PC2 domain. The calpain 6 is the only member that does not have a catalytic triad; there is Lys instead of Cys. In the absence of $\mathrm{Ca}^{2+}$ ions these two domains are far from each other and thus the catalytic triad is not assembled [8]. Both domains can bind $\mathrm{Ca}^{2+}$ ion and that results in structural changes opening of the active site cleft and assembling the catalytic triad [9] (the relationship between the structure and activity is well summarised in Ref [10]). Although the whole 3D structure of only calpain 2 is known (Fig. 2A) [9,11], using this for 3D modelling of other calpains is an accepted strategy [12,13].

\subsection{Physiological role of Calpains}

\subsubsection{Regulation of enzyme activity}

Calpains are expressed in different organisms, for example in human, invertebrates, yeast, other fungi and bacteria. These intracellular enzymes cleave their substrate proteins in welldetermined manner. This limited proteolysis activates or deactivates the substrate proteins, thus calpains have regulatory or signalling function, rather than protein digestion in cells like proteasomal or lysosomal enzymes do. Because of this, their activity should be under strong 
control in cells. Two proteins of calpain regulation are well-studied and play vital roles. One is the small regulatory subunit (calpain 4) that is necessary to stabilise the structure of at least calpain 1 and 2 [14]. The other protein is the calpastatin that has inhibitory effect on dimeric calpains (e.g. calpain 1 and 2) [15]. Beside them, the $\mathrm{Ca}^{2+}$ ion concentration is the main factor. At increased $\mathrm{Ca}^{2+}$ ion concentration these enzymes are activated, although this happens only at high concentration (3-50 $\mu \mathrm{M}$ and $0.4-0.8 \mathrm{mM}$ for calpain 1 and 2 , respectively) in vitro. This is highly above the intracellular $\mathrm{Ca}^{2+}$ ion concentration $(<0.05 \mu \mathrm{M})$. Thus, other mechanisms should be involved in the activation of calpains (e.g. relocalisation into mitochondria or nucleus; membrane binding, phosphorylation) [16].

\subsubsection{Studying the function of calpains}

In the first experiments, calpain functions were assumed from the intracellular role of in vitro identified substrate proteins; or changes in the cell properties caused by calpain inhibitors. Nowadays, as there are no very specific calpain inhibitors available, at least for calpain isoforms, silencing of activity or using transgenic mice are the commonly applied techniques. As the two conventional calpains (1 and 2) are present in all cells, their functions are the most extensively studied. Although more than 100 proteins were identified as calpain substrates in vitro [4], this does not imply that calpain cleavage also happens in cells (e.g. some extracellular proteins are cleaved by calpain in vitro too).

\subsubsection{Biological functions of conventional calpains; Calpain 1 and 2}

The earliest specified and most studied actions are their role in cytoskeletal remodelling and cell motility [17]. In these events, calpains regulate the attachment of cytoskeletal proteins to the cell membrane or the focal adhesion disassembly [18]. As many enzymes (kinases, phosphatases) and cytoskeletal proteins involved in signal transduction are cleaved by calpains, they are supposed to be involved in signal transduction [19-21] too. 
There is some evidence that calpain 1 and 2 take part in the regulation of cell cycle (via cyclin D1) [22], cell proliferation (cleavage of p53) [23], transformation (by v-Src) [24], neural stem cell differentiation [25]. The latest is very interesting, because calpain 2 triggers, while calpain 1 represses it. Besides the role in cell differentiation, calpains have essential functions in the nervous system, like nerve-cells development [26]. There is increasing evidence that the two ubiquitous isoforms (calpain1 and 2) have distinct impact on the memory formation and neurodegeneration [27,28]. They also play different roles in the angiogenesis. Vascular endothelial growth factor (VEGF) evoked only calpain 2 and not calpain 1 activation in angiogenesis [29]. It seems that VEGF is the main activator of calpain 2 in endothelial cells [30]. Calpains are involved in wound healing and embryonic development under physiological conditions via angiogenesis [31,32]. During wound healing, in contrast with calpain 2, calpain 1 enhances the dissociation of vessels in the middle or late stage [33]. In embryonic development, calpains contribute to the formation of adequate vasculature for organ development [32]. The mutant embryos died at midgestation and had abnormal cardiovascular system. Later it was shown that only knockout of calpain 2 resulted in the death of embryos [34,35], while embryos without calpain 1 were viable and fertile [36]. The role of calpains in the embryonic development is reviewed in Ref [37].

Studies showed that calpains are important effectors of the immune response. Their activity is essential for protein secretion by macrophages [38], for the regulation of NLRP3 inflammasome [39], in pyroptosis [40] and T-cell activation [41].

\subsubsection{Physiological functions of unconventional calpains}

Although more unconventional calpains have been identified lately, their physiological functions are poorly described. One of the most studied isoforms is calpain 3, which is especially abundant in skeletal muscle. Unlike calpain 1 and 2, this isoform is a homodimer, thus the small regulatory unit is not necessary for its activity [42]. The structure of its protease 
core domain has been determined [43]. Although our knowledge about its physiological role is not complete, its missing activity (proteolytic and non-proteolytic), caused by mutation, is responsible for muscular dystrophies (e.g. limb-girdle muscular dystrophy type 2A (LGMD2A)) [42]. Calpain 5 is mainly expressed in the retina and in the synapses of photoreceptors. Similarly to calpain 3, our knowledge is restricted about its normal functions, but several mutations are known which disturb its activity and thus result in pathological alterations (e.g. vitreoretinopathy) [44,45]. Calpain 8 and 9 are dominantly expressed in the stomach. Mice without these enzymes are susceptible to ethanol-induced gastric ulcer, indicating that both proteins play protective roles in the gastric mucosa [46]. These enzymes form a protease complex, "G-calpain" with dual enzyme activity. Calpain10 is a non-classical calpain and was proved to be the first susceptibility gene for type 2 diabetes mellitus. There is evidence that it has a role in insulin secretion and insulin-stimulated glucose uptake [47].

\subsection{Role in diseases}

The disturbance in the calpain activity often results in pathological disorders in cells and thus play critical role in diseases [48] (Table 2). Often the turmoil in $\mathrm{Ca}^{2+}$ ion homeostasis is behind the abnormal calpain behaviour. Sometimes the normal activity is not well-known, but symptoms caused by increased or decreased calpain action are well-studied. For example, there are some indications that calpains may have a role in apoptosis under physiological conditions, but their activity in cell death in degenerative diseases is well-described $[49,50]$.

\subsubsection{Symptoms caused by overactivated calpain}

In degenerative disorders (e.g. Alzheimer' disease (AD), degenerative vascular disorders, skeletal muscle atrophy), it is proved that disturbance in intracellular $\mathrm{Ca}^{2+}$ ion homeostasis results in overactivation of calpains and then cell death [51-53].

It is well documented that increased calpain activity plays crucial role in the pathogenesis of Alzheimer's disease [51]. Different signals increase the $\mathrm{Ca}^{2+}$ ion concentration and thus the 
overactivated calpains act in more than one way (e.g. producing amyloid beta $(A \beta), \tau$ hyperphosphorylation, impairing learning and memory ability) to produce the syndromes of AD. Calpains have many substrates taking part in the AD pathology. The overactivated calpain cleaves p35, the neuron-specific Cyclin-dependent kinase 5 (CDK5) activator, into p25 which is a more potent CDK5 activator [54]. The prolonged activity of CDK5 enhances the production of beta APP cleaving enzyme 1 (BACE1), thus increasing the formation of $\mathrm{A} \beta 40$ and $\mathrm{A} \beta 42$ [55]. The produced $\mathrm{A} \beta$ can trigger the $\mathrm{Ca}^{2+}$ ion influx and thus increases the calpain activity [56]. The CDK5 and glycogen synthase kinase-3 (GSK3) can be activated by calpain [54,57], and these kinases among others are responsible for the phosphorylation of $\tau$ protein $[58,59]$. Finally this intracellular hyperphosphorylated $\tau$ protein makes neurofibrillary tangles.

Enhanced calpain activity has important effects in several chronic vascular degenerations (e.g. atherosclerosis, aneurysms, diabetic angiopathy/retinopathy) (reviewed in Ref [52]). Calpain 1 and 2 are involved in angiotensin II induced atherosclerosis [60,61], and some evidence suggests that calpain 2 also has a role in this via the proteolysis of VE-cadherin causing barrier dysfunction between endothelial cells [62]. Calpains may also regulate the fate of VEcadherin by proteolytic cleavage of its C-terminal [63]. It is worth noting that calpain 6, a non-classical and unique calpain without proteolytic activity, takes parts in atherosclerosis via binding to splicing factor CWC22 and inhibiting its nuclear translocation [64].

Although calpain 1 and 2 are mainly localised in cytoplasm, they are present in the mitochondria too. The activity of calpains in cardiomyocyte mitochondria are increased under different stress conditions. In a recent study it was demonstrated that increased mitochondrial calpain 1 activity is connected with myocardial injury and heart failure by disrupting ATP synthase [65]. 
Myofibrils in skeletal muscle contain many proteins which can be cleaved by calpains. Thus, increased calpain activity leads to the releasing of myofilaments and small protein fragments which are hydrolyzed by the ubiquitin system. Meanwhile this calpain cleaves heat shock protein90 and thus reduces the Protein kinase B (Akt) activity in the muscle. Both events result in muscle atrophy. (reviewed in Ref[53]).

The role of calpains in injury (e.g. stroke, traumatic spinal cord and brain injury) causing neuronal cell death is also described (reviewed in Ref $[66,67]$ ). This is the result of $\mathrm{Ca}^{2+}$ ion flood into neuronal cells overactivates calpains. Often only calpain 2 is responsible for cell death in these symptoms (reviewed in Ref [68]). The traumatic brain injury (TBI) can evoke many cascades, which result in further damage in the brain. The $\mathrm{Ca}^{2+}$ ion is one of the main mediators of these processes. Among the $\mathrm{Ca}^{2+}$ ion dependent proteases the calpain is the most important in the proteolysis of neuronal-cytoskeletal elements [69], like the essential cytoskeletal protein $\alpha$-II-spectrin [70]. Recently it was shown that calpain 1 and 2 may have distinct roles in TBI [71]. The results showed that calpain 1 activity decreased while calpain 2 activity increased neurodegeneration after TBI.

\subsubsection{Calpain activity in tumorigenesis}

Calpain 1 and 2 are overexpressed in many kinds of tumour cells, and they have different roles in tumorigenesis (reviewed in ref [72]). Roles of calpains in apoptosis of tumour cells are contradictory. Dependent on the type of cancer, on the death stimuli, they can help to survive or to induce apoptosis [73]. In case of tumour surviving they cleave one of the proteins involved in apoptosis (e.g. cleavage of Myc oncoprotein [74]). Proteolysis of caspases (e.g. caspase 7 [75]) or anti-apoptotic proteins (e.g. Bcl-2 and Bcl-xL [76]) results in cell death. They can increase not only the tumorigenesis, but metastasis as well [77]. Besides calpain 1 and 2, other members also have important roles in numerous cancers. In colorectal cancer the gene of calpain 4 is overexpressed and it is in good correlation with tumour 
progression and poor survival [78]. The overexpression in vitro increased, while knockdown of this gene decreased the proliferation of cancer cells both in vitro and in vivo. It influences the expression of MAPK7 (mitogen-activated protein kinase7) kinase via Wnt/ $\beta$-catenin pathway. Calpain 4 has roles in other tumours to (e.g. melanoma, ovarian carcinoma) $[79,80]$. Decreased expression of calpain 9 means bad prognosis in gastric cancer [81]. Although it forms complex with calpain 8 , only the amount and activity of calpain 9 has influence on the tumour fate. Calpain 9 overexpression arrests cells in G1 phase and attenuates the size of tumour xenografts in vivo.

Calpain 2 has role in angiogenesis, in which it is activated by VEGF [30] both in physiological and pathological conditions, e.g. tumour angiogenesis. Recently it was proved that hypoxia could induce the proteolysis of filamin A by calpain in melanoma cells and thus it can increase tumour angiogenesis [82].

\subsubsection{Diseases with decreased calpain activity}

The most studied and best-known disease which is connected to the decreased calpain activity is the limb-girdle muscular dystrophy. In this disease the activity of calpain 3 enzymes is not sufficient, because of mutation in its gene (CAPN3 gene) [83].

In diabetes, the growth factors and their receptors (e.g. VEGF, platelet-derived growth factor (PDGF)/PDGF receptor, FGF/FGF receptor, EGF) are down-regulated, thus there is not adequate calpain 2 activity for wound healing [31]. Overexpression of calpain 2 promotes the wound healing in diabetes [84].

The gene of Calpain10 has been proved to be the first susceptibility gene for type 2 diabetes mellitus. This enzyme has critical roles in insulin secretion and thus the insulin-stimulated glucose uptake [47]. Recently it was shown that Calpain 10 cleaved the microtubuleassociated protein 1B (MAP1B) and other MAP1 family members. The cleavage results in a heavy chain and a light chain, and affects the binding ability of the MAP1B to microtubules. 
Thus, decreased amount of calpain 10 has influence on insulin secretion by abnormal actin reorganization, coordination and dynamics [85].

These examples show that overactivation of calpains has critical roles in several diseases. Therefore, inhibitors which can decrease or diminish this overactivation may be useful in the treatment of these pathological disorders.

\section{Inhibitors}

Increased calpain activity plays critical role in several pathological disorders resulting in diseases (e.g. neurodegenerative diseases, cancer). Decreased calpain activity (e.g. gene knock out) or overexpression of calpastatin may diminish or reduce the symptoms of these pathological conditions [86-88]. These findings suggest that inhibition of calpain activity is a promising therapeutic target in these diseases. In calpain regulation there is an endogenous protein, calpastatin, that is a very specific inhibitor for calpain 1 and 2 [15]. Its use is very attractive; however, it has several drawbacks as a therapeutic agent (e.g. administration, in vivo stability and poor internalisation) that come from its protein nature and size. The minimal inhibitory sequence is a 27-mer peptide that is very good and specific inhibitor [89], but can poorly internalise into cells. Albeit its usage is not easy, the 3D structure of its inhibition manner $[9,11]$ may provide a basis for the design of small molecule inhibitors.

Leupeptin (Ac-Leu-Leu-Arg-H), a microbial inhibitor was used to inhibit cysteine proteases [90] and was the base of the development of MDL 28170 (Z-Val-Phe-H) [91]. Using these structures several peptidomimetic inhibitors have been developed. These inhibitors have substrate peptide properties and bind to the active site cleft. At the position of scissile amide bond, there is a reactive functional group "warhead" like carbonyl group (in aldehyde, $\alpha$ ketoacids, $\alpha$-ketoamides, and $\alpha$-ketoesters), epoxysuccinate, disulfide group or azaaminoacids (reviewed in Ref $[92,93]$ ). The warhead, an electrophilic functional group, reacts with the thiol group of Cys in the active site in reversible or irreversible manner. 
Unfortunately, the substrate specificity of calpains depends on the structural features of the cleavage site rather than on its sequence. Some effort has been done to identify a substrate sequence with high affinity and selectivity towards calpains $[94,95]$. These sequences may be the starting point of inhibitor design.

\subsection{Calpastatin based inhibitors}

Calpastatin is an endogenous and unique specific calpain inhibitor [15]. Like calpain 1 and 2 it is also expressed ubiquitously. Its expression level is higher than those of calpains [96]. Calpastatin has four repetitive inhibitory domains, each capable of binding to one molecule of calpain (Fig. 1B) [97]. Each domain comprises of three small subdomains, A, B and C. Only the subdomain B binds directly to the active site of the calpain and is responsible for the inhibitory effect [98]. The manner of its inhibition is interesting (Fig. 2B). The calpastatin is an intrinsically unstructured protein, which can bind reversibly only to calcium bound calpain [99]. While the inhibitory domain binds to the calpain, it forms three helixes. Two of them are in the subdomains $\mathrm{A}$ and $\mathrm{C}$ and these helixes bind to the penta-EF-hand domains (Fig. 2B) [9,11]. The third, forming a two-turn amphipathic $\alpha$-helix in the subdomain B on its $C$ terminal side, binds next to the active site cleft. The Leu ${ }^{173}$ occupies the $S_{2}$ while $\mathrm{Thr}^{179}$ the S' ${ }_{1}$ subsite. The region between them (Gly ${ }^{174}$-Ile-Lys-Glu-Gly ${ }^{178}$ ) fits into the active site but forming a kink to avoid proteolysis [11]. Although the full inhibitory domain has a role in the inhibition, it turned out that a 27-residue peptide corresponding with the subdomain B sequence $\left(D^{1}\right.$ PMSSTYIEELGKREVTIPPKYRELLA ${ }^{27}$ ) can inhibit the calpain enzyme with similar efficiency and selectivity as the calpastatin protein [89]. Highlighting the importance of subdomain B, inhibitors can be synthesized based on its sequence. Studying its inhibitory mode (the full domain or the subdomain B) and using its 3D structural information we can get new weapons to design effective and specific inhibitors. 
Although calpastatin B peptide is a very efficient inhibitor, it is poorly cell-permeable. However, it was successfully used to inhibit calpain in live cells or in animal model $[100,101]$. To solve this challenge, some conjugates with cell-penetrating peptide were synthesised [102-106]. Oligoarginines are positively charged cell-penetrating peptides (CPPs). To enhance the internalization of calpastatin B peptide it was conjugated with undecaarginine $\left(\operatorname{Arg}_{11}\right)$ [102]. This synthetic conjugate could inhibit isolated calpain 2 and calpain activity in primary cultured neurons. Penetratin, another well-known CPP, has been conjugated via disulphide bridge with the subdomain B peptide [103]. The conjugate retained the inhibitory potency against calpain 1 and its selectivity over other cysteine proteases. It showed cell-permeability on LCLC $103 \mathrm{H}$ cells (human large cell lung carcinoma), and inhibited the ionomycine-induced calpain activation in these cells. A shorter segment of the penetratin was also considered, where a 7 -mer from the $C$-terminal was chosen as a CPP [104]. The cationic peptide was conjugated to subdomain B, resulting in a cell permeable inhibitor. The conjugation was done via amide or disulfide bond. Both connection modes produced effective inhibitors. As the calpastatin protein is more effective inhibitor than its subdomain $\mathrm{B}$, its fusion protein with Tat peptide (a cell-penetrating peptide) was also studied [105]. The fused protein was able to inhibit calpain 2 in vitro, but was not able to inhibit calpain activity in rat primary cortical neurons. As the construct could penetrate into cells, the localisation of the construct, entrapped in the endosome, hinders the interaction with calpain enzymes in the cytosol.

An elegant structure-activity analysis was done using $\beta$-Ala scan in calpastatin B peptide [107]. Two "hot spots" were identified in the sequence, Leu ${ }^{11}$-Gly ${ }^{12}$ and Thr $^{17}$-Ile-Pro ${ }^{19}$. In another study the importance of $\mathrm{Leu}^{11}$ and $\mathrm{Ile}^{18}$ was proved [108]. The minimal inhibitory sequence was described as a 20-mer peptide (Ac-SSTYIEELGKREVTIPPKYR) [109]. Using these results a new cell-penetrating derivative of calpastatin B was synthesised with efficient 
Blood Brain Barrier (BBB) penetration [110]. In this study, the $\mathbf{V}^{23} \mathbf{A L L P} \mathbf{P}^{27}$ AVLLALLAP cell-penetrating peptide was hybridized with calpastatin B peptide (27-mer peptide) in such a way that the amino acids, $\mathbf{V}^{23} \mathbf{A} \mathbf{L} \mathbf{L} \mathbf{P}^{27}$, replaced the corresponding amino acids in the calpastatin B peptide. The construct was able to penetrate through the BBB and inhibit calpain 1. The effect was evident, since the administered construct minimized neurological deficits by $35 \%$ and $44 \%$.

From the structure of calpain-calpastatin complex $[9,11]$ it turned out that during the binding the calpastatin forms three $\alpha$-helixes and one of them, a two-turn helix binds next to the active site on the prime side. Unfortunately, this short peptide (IPPKYRELLA) has random coil structure in solution and does not adopt helical structure. Thus, it does not have any inhibitory effect [111]. The authors stabilized the peptide by increasing the rigidity via macrocycle formation by Cys alkylation. Using i, i $+4 m$-xylene cross-linker and changing the position of the two Cys residues in the sequence, macrocycles with different sizes were synthesised. A derivative in which the Ala and Arg residues were replaced with Cys showed the highest helix content and inhibitory activity against calpain 1 . Beside this helix there are other structural elements which are important in the calpastatin inhibition and may be templates for specific inhibitor design. When the calpastatin binds to the calpain, it avoids the cleavage, because the subdomain B forms a $\beta$-turn, at Lys-Leu-Gly-Glu (calpastatin B in inhibitory domain 3) [9]. Using this $\beta$-turn forming sequence a set of cyclic peptide library was tested [112]. By cyclisation the disordered short peptides could be forced into a well-defined structure like $\beta$ turn [113]. Furthermore, the cyclisation protects the peptide from proteolysis. Each peptide in this study had a Pro residue at the N-terminus, where aziridine aldehyde-derived macrocyclisation was performed. Some peptides were not only effective inhibitors, but also specific for calpain 2 over other cysteine peptides used. 
These examples demonstrated that the specific inhibitor calpastatin or its inhibitory subdomain B can be applied as calpain inhibitors, but their delivery should be solved because of their low permeation. Conjugation with cell-penetrating peptides as delivery vehicles may increase the cellular uptake. However, they highlight the importance of the size (full calpastatin protein $v s$ calpastatin B peptide) in the efficient penetration. Targeting CPP may enhance the specific transportation through the BBB or into specific tissues. Using structural information of calpastatin's mode of inhibition also may promote the development of effective inhibitors.

\subsection{Substrate based inhibitors}

Design of inhibitors against protease enzymes historically focused on the substrate specificity. A peptide with electrophilic warhead can fit into the active site cleft as a substrate and thus it reacts with the amino acid in the active site in a reversible or irreversible manner. Against cysteine proteases many warheads can be used. Unfortunately, two factors mean serious challenges in the development of this kind of inhibitors; a) the highly conserved active site among the members of papain superfamily and b) the binding of small peptides to calpains is not very strong. Therefore, the selectivity of inhibitors against other cysteine proteases, like cathepsins may be very important [114]. Inhibition of cathepsin C, L and S induces immunosuppression, but on the other hand, inhibition of cathepsin $\mathrm{B}$ and $\mathrm{K}$ is not considered detrimental. The firstly identified peptide-based inhibitors had several disadvantages, like poor water-solubility and metabolic stability, low cell-penetration. Thus, one strategy is the replacement of amino acids in these di- or tripeptide inhibitors (e.g. aldehydes, [115] leupeptin (Ac-Leu-Leu-Arg-H), MDL28170 (Z-Val-Phe-H)) and thus improve at least the stability (Fig. 3).

The structure of MDL 28170 was used to develop peptidomimetic inhibitors. The purpose of these studies was to find more selective and stable inhibitors. The strategy was to replace 
amino acids in the $\mathrm{P}_{2}-\mathrm{P}_{3}$ position in the well-known MDL-28170. Chromone skeleton was selected and substituted carboxamide was used as the reactive warhead [116]. Replacement of Val residue with chromone ring produced a cyclic derivative of MDL 28170 (1) with similar potency to MDL 28170, with improved selectivity against cathepsin B and cathepsin L. Replacement of the oxygen atom in the pyran ring with -NH group, using 4-quinolinone ring (2), provides the construct with an additional donor for $\mathrm{H}$-bonding. That may improve the binding to the active site [117]. Although these constructs were potent, their activity was less than that of chromone based ones. Furthermore, acyclic construct based on these two structures were considered with more flexibility [118]. The proposed constructs were expected to interact with high potency due to their acyclic structures. Substituents on the aromatic ring (no substituents were added to the Phe aromatic ring) were considered as $\mathrm{H}$ bond acceptors or donors, and methoxy substituents had a positive effect on the inhibition (3). Using similar strategy, a selective and metabolically stable inhibitor was developed, A1212805 (ABT-957, Alicapistat) [119]. Starting from the structure of MDL28170 it was noticed that benzoyl modified phenylalanine derivatives can be potent inhibitors [120]. Although it had $\mu \mathrm{M} \mathrm{K}_{\mathrm{i}}$ value, modification of the benzoyl ring in ortho position could increase the inhibitory potency. The naphthalene derivatives were the best with $n M K_{i}$ value. The comparison of inhibitors with aldehyde and ketoamide warhead showed no differences in the calpain inhibition. This means that ketoamide group instead of aldehyde may enhance the stability of the inhibitors. The most potent inhibitor was selective against cathepsin B and L. Derivatives with phenylvinyl substituent in the benzoyl moiety andaminomethyl residue as para-substituents were good inhibitors with oral bioavailability, water solubility and metabolic stability [121]. One of them, (N-(1-benzyl-2-carbamoyl-2-oxo-ethyl)-2-[(E)-2-(4diethylaminomethylphenyl)-vinyl]benzamide (A-705253)), showed efficacy in experimental traumatic brain injury in rats. In some studies this kind of inhibitors was active in AD-relevant 
animal models (e.g. decreased the tau hyperphosphorylation, neurodegeneration) $[122,123]$. Although it was used promisingly in these studies, it was poorly selective against cathepsin enzymes. This requirement induced further optimalisation of inhibitor A-705253 [124]. By the modification of the structure a very active and specific in vitro peptidomimetic inhibitor was obtained (N-(4-Amino-3,4-dioxo-1-phenylbutan-2-yl)-2-(3-(4-fluorophenyl)-1H-pyrazol1-yl)nicotinamide (A-953227)). Unfortunately, in in vivo studies the ketoamide group could be observed and this transformation decreased dramatically its bioavailability. Although modification of the ketonamide group reduced the inhibitor potency, it may enhance the in vivo stability [125]. The collected information about structure-activity relationship (SAR) was used to develop ABT-957 [119]. This drug was used in clinical phase 1 studies for studying its activity in treatment of Alzheimer disease [126]. Unfortunately, it was ineffective on REM sleep parameters, which indicates that its concentration in the central nervous system was not adequate, although it was effective in animal models [119].

These selected examples highlight the commonly used strategies, using systematic chemical modifications, to improve the pharmacophore properties of calpain inhibitor. In these studies the starting compound was a well-characterised inhibitor and it was modified to cover different chemical spaces. The resulted SAR data directed the further optimization. Another strategy to get more efficient drug-like inhibitors can be the modification of inhibitors with targeting moieties that may enhance the penetrating ability through cell membrane or blood brain barrier (BBB) (Fig. 4). For example, to improve the internalisation into the muscle cells, peptide based inhibitors with $\alpha$-ketoamide functional group on the $C$-terminal were modified by groups that may increase the penetration [127]. The retained inhibitory potency for treating muscular dystrophy was an important aspect of modification. Using the MDL28170 as a template the best capping group in $\mathrm{P} 3$ position was selected based on the in vitro inhibitory ability in muscle cells. Then the P2 and P1 residues were optimised. The potency of 
derivatives was characterised on calpain 1 and on some other cysteine proteases to describe the selectivity. One of the best derivatives was further improved to increase its cellpermeability into muscle cells (4) [128]. The best compound showed therapeutic efficacy in muscle dystrophy using mouse model.

AK925 (Z-Leu-D,L-Abu-CONH-R; Abu is $\alpha$-aminobutyric acid) is a peptidomimetic $\alpha$ ketoamide calpain-1 and calpain-2 inhibitor that demonstrates neuroprotection against brain ischemia [129]. However, the construct could not penetrate through the BBB. In order to synthesise a permeable construct, nucleobases, such as adenine and 2-methoxyadenine were incorporated into the structure, because choline transporters would transport these conjugates through the BBB [130]. The nucleobases were coupled to the primed region, since inhibitors that extend to the primed region are more potent [131]. This modification resulted in potent inhibitors that are able to cross the BBB (5). This strategy was used to develop Gabadur [132]. This construction was designed based on the structure of leupeptin. The $N$-terminal leucine was substituted by pregabalin via succinic-acid linker. The pregabalin, which is a substrate of system L-amino acid transporters, increased dramatically the blood-brain penetrating ability opposed to the poorly permeable leupeptin molecule. The inhibitor with rapid BBB penetrating ability was successfully used in animal models of traumatic brain injury [133], and Parkinson's disease/dementia with Lewy bodies [134].

As it became more evident, calpain isoforms often have distinct roles in physiological and pathological conditions. Sometimes their activity has opposite effect (e.g. calpain 1 and 2 in nervous system [27]). Thus, finding isoform selective calpain inhibitors is very attractive, and may result in a breakthrough in calpain research. These kinds of inhibitors can strengthen the therapeutic potency of calpain inhibitors. Although this research area is very challenging, there are some promising endeavouring. Targeting the mitochondrial calpain 10, peptide screen was used to identify selective inhibitors [135]. In this screen, hexapeptides were tested. 
The initially described CYGRKK peptide was further improved. The role of some amino acids in the potency was investigated and a 5-mer peptide was found as the most potent (CYGAK). Its dimer was selective and potent towards mitochondrial calpain 10 over calpain 1. Unfortunately, it could inhibit calpain 10 activity only at higher concentration in cellular models than that needed for isolated mitochondria. To improve the potency against cellular calpain 10, molecular modelling was done on a homology model of the calpain 10 active site [136]. Although using the interacting residues of the peptide a better inhibitor was found (CYGAbuK), it could not inhibit mitochondrial calpain 10 in cells. Increasing lipophilicity by conjugation of oleic acid enhanced this ability.

In another study, development of isoform specific inhibitors was aimed using the interaction with $S_{3}$ pocket [137]. Interaction of this site of cysteine proteases with a heterocycle often resulted in potent inhibitors. Heterocyclic dipeptide aldehydes ( 9 analogues) were synthesised and some showed isoform selectivity for ovine calpain 2 (ovine calpain was used because the inhibitors were studied in ovine model of cataract). To analyse the SAR data, in silico homology models were generated using h-CAPN1 X-ray crystal structure data. The most potent and ovine calpain 2 selective inhibitor (6) showed different interaction with the active site of ovine calpain 1 and 2, explaining its selectivity. This compound could inhibit calciuminduced opacification in in vitro lens culture assay. In order to increase the potency, more heterocyclic (furan or thiophene) dipeptide analogues (7) were synthesized [138]. Spacers were included and the position of the heterocycle (position 2 or 3 ) in which the peptide is attached was changed. Relationship was described between the mode of connectivity and inhibition; compounds in which the peptide is coupled to position 3 were more potent than compounds in which the connection was in position 2. Moreover, spacing seemed to diminish the inhibitory effect. Molecular modelling revealed that the peptide backbones of potent inhibitors adopt the requisite $\beta$-strand conformation. 
The $\beta$-strand geometry is a universal conformation that is presented by protease inhibitors upon binding in the active site [139]. Macrocyclic peptides can adopt $\beta$-strand geometry and can be more selective [140] and potent [141] in contrast to their linear counterparts. Adjusting the size of the macrocycle the selectivity and the potency of calpain inhibitors can be modified (8) [142]. Isoform selectivity, calpain 2 over calpain 1 was observed too. In a different inhibitor a tripeptide was used to form a macrocycle which also presented good inhibitory potency against calpain 2 (9) [143]. The potency was in good correlation with the ability of macrocycles to from $\beta$-strand geometry. Development of this kind of macrocycle as a template may give good opportunity to improve inhibitors of different proteases, like calpain 2 [144].

By extending the structure of inhibitors towards the primed region, their activity and specificity can be ameliorated. The elongated structure may serve more groups for interaction and thus may increase the strength and selectivity of binding. There are several warheads (e.g. azaamino acids, epoxysuccinylogrup) that allow this kind of extension of inhibitors. Replacing the $\alpha$-carbon of the amino acid $\mathrm{P}_{1}$ with nitrogen atom leads to an azapeptide [145]. Thus the amino acid P1 is formally a derivative of carbazicacid $\left(\mathrm{H}_{2} \mathrm{NNRCOOH}\right)$. These azapeptides were able to inhibit serine proteases and some aza-peptides were also examined on cysteine proteases [146]. To create a set of oligopeptides that may be potent calpain inhibitors, aza-glycine $\left(\mathrm{NH}_{2}-\mathrm{NH}-\mathrm{COOH}\right)$ was inserted into the sequences [147]. The sequence of these azapeptides was selected based on a potent substrate, TPLKSPPPS [94]. The replacement of Lys at the P1 position with aza-glycine yielded good inhibitors. Epoxysuccinyl group presented in an effective and selective cysteine protease inhibitor, trans-Lepoxylsuccinyl-L-leucylamido-4-guanidino-butane (E-64)[148] (Fig. 5 A)), as warhead allows the synthesis of inhibitors that are expanded to the primed region. Using this approach, the aforementioned peptide (TPLKSPPPS) was modified by including an epoxysuccinyl 
group [149]. It was noted that the stereochemistry of the epoxy group is quite important, since it affects the orientation of the inhibitor in the active site. With the aim to improve the selectivity and potency of the natural inhibitor E-64, peptidomimetic analogues based on E-64 scaffold were prepared [150]. The design of the analogues focused on investigating the capping groups at the $\mathrm{P} 3 / \mathrm{P} 4$ positions and studying various amino acids at the $\mathrm{P} 2$ position. By screening for different entities at $\mathrm{P} 2$ and $\mathrm{P} 3 / \mathrm{P} 4$ positions, potent inhibitors that are selective for calpain1 were synthesized (10).

Modelling can provide a valuable tool to develop and design calpain inhibitors. For docking studies structural data are commonly subtracted from crystal structures of full calpain or its domain. In a study the structure of the $\mathrm{Ca}^{2+}$ ion bound crystal structure of the protease core of calpain 1 (PDB code 1KXR) was modified. The Ser115 was changed with Cys in this position to reproduce the structure of the active form [151]. This model was validated by inhibitors with known potency for docking and then it was used to screen potential inhibitors. In molecular docking the studied structures were modified only in one position at a time and tested. Inhibitors with the highest scores were tested for inhibitory action, resulting in excellent $\mathrm{IC}_{50}$ values. Additionally, the best inhibitor was able to reduce cataract in ovine lenses. In another approach a large chemical library from Maybridge database (53 000 druglike compounds) was screened [152]. First, compounds were filtered based on their calculated absorption, distribution, metabolism and excretion (ADME) properties. The remaining compounds (the standalone library) were subjected to High Throughput Virtual Screening (HTVS). They were docked into a similar model used in the previous study [151]. Binding energy calculation and molecular dynamic simulation were applied to find the best compounds. That was investigated in an in vitro rat model of selenite-induced cataract, and it exhibited suppression in cataract formation. In a similar study the well-known calpain inhibitors were used to build up a pharmacophore model (template) which then was used in 
the virtual screening of a Binding Database for 'hit' molecules (molecules with similar chemical features than those of the pharmacophore) [153].

Interestingly, computational approaches where also used to search for allosteric inhibitors of calpain. Using a model based on the structure of PEF, the small subunit of calpain 1, a library of inhibitors was screened. The study resulted in a good allosteric inhibitor of calpain 1 (see in the next chapter) [154].

The previous results show how modelling can be a good step in the discovery of potential calpain inhibitors. Its use gives a notably valuable method to increase the potential chemical space to identify candidates as good calpain inhibitors.

\subsection{Allosteric inhibitors}

As the active site cleft among the cystein proteases is homologous, it is very challenging to increase the specificity for calpains over other proteases. Compounds that can bind to other positions on the enzyme surface may cause allosteric inhibition and may be more specific. The first allosteric inhibitor was identified from a 150,000 library, screening calpain 1 inhibition [155]. The structure of the firstly discovered compound was refined and thus an efficient calpain specific inhibitor, 3-(4-iodophenyl)-2-mercapto-(Z)-2-propenoic acid (PD150606) was described (Fig. 5 B)). It was supposed to bind to the $\mathrm{Ca}^{2+}$ ion binding site of the enzymes. One derivative, 3-(5-fluoro-3-indolyl)-2-mercapto-(Z)-2-propenoic acid (PD151746) is approximately 20 -fold more selective for calpain $1\left(\mathrm{~K}_{\mathrm{i}}=0.26 \mu \mathrm{M}\right)$ over calpain $2\left(\mathrm{~K}_{\mathrm{i}}=5.33 \mu \mathrm{M}\right)$. The crystal structure of $\mathrm{Ca}^{2+}$ ion bound calpain domain VI and PD150606 complex revealed the binding mode of the inhibitor to the penta-EF-hand [156].

As calpain 1 and 2 have different $\mathrm{Ca}^{2+}$ ion sensitivity, this kind of inhibitors are promising candidates to develop isoform selective inhibitors. A new series of mercaptoacrylicacid derivatives was reported. They investigated the effect of halogen substitution in the phenyl- or indole-ring on the inhibitory activity. The results of this SAR study showed that the 
previously reported PD150606 and PD151746 are members of a larger family of calpain inhibitors. The bromo-substituted indole derivatives showed the highest inhibitory potential with sub-nanomolar $\mathrm{IC}_{50}$ range on calpain 1 and the best compounds could inhibit neutrophil spreading too [157]. As calpain 1 is a potential drug target and its specific inhibitors may have high influence on the calpain research, structural elements of binding of these molecules was examined [158]. The co-crystal structure of human calpain PEF(s) and its inhibitor complexes were described. Two inhibitors were studied, one with indole ring (and (Z)-3-(5-bromoindol3-yl)-2-mercaptoacrylic acid, 11) and one with phenyl ((Z)-3-(4-chlorophenyl)-2mercaptoacrylic acid, 12). Results showed that mainly the hydrophobic interactions have impact on the stability of complexes. The indole ring bound more deeply to the $\mathrm{Ca}^{2+}$ ion binding pocket of the PEF, than the phenyl-group. Using this SAR the dimers of some monohalide-derivatives of phenyl and indole 2-mercaptoacrylic acid were studied [159]. These compounds were synthesized to mimic the binding of calpastatin to the hydrophobic cave on the PEF(S). The dimers showed approximately 10-200-fold higher inhibitory effect than the compound with free thiol group. Furthermore, replacement of the disulfide bond with thioether bond reduced the activity of the compounds. This was explained with the stereoelectronic behavior of disulfide bond, such as restricted rotation and $\sim 90^{\circ}$ dihedral angel. This geometry increases the number of opportune binding interactions between $\operatorname{PEF}(\mathrm{S})$ and the two aromatic rings.

Later it turned out that PD150606 was able to inhibit the calpain 1 protease core unit without PEF. This result shows that its inhibitory activity does not require PEF and it has a single mode of inhibition [160]. Specific calpain 1 inhibitors may be beneficial because they do not cause undesirable physiological side effects. These kinds of inhibitors were developed using a structure-based virtual screening protocol [154]. First 36000 commercial compounds were studied by docking methods (such as sulphonamide-, amide-, pyridine-, urea- and enamine- 
based compounds). The selected candidates were further analyzed against PAINs [161]. Ten compounds were selected as potential PEF(s) binding compounds, those cover novel chemical space among the allosteric inhibitors of calpain 1. Some of them showed allosteric inhibitory activity in in vitro assays (FRET based inhibition assay on full length calpain-1 complex and active site domain calpain-1 (without PEF motifs) and TNS displacement assay). The best compound was an asthma drug, Vidupiprant, which had higher inhibitory activity than PD150606. This finding is in good correlation with earlier results that anti-inflammatory drugs could inhibit calpain and thus reduced the allergic inflammation [162].

\section{Activators}

Although it is a rarer event, but decreased calpain activity also has a role in pathological conditions (e.g. wound healing in diabetes [31], LGMD2A [42], gastric ulcer [46], tumor survival [81], diabetes mellitus [47]). Therefore, activation of calpains in these symptoms may compensate these harmful changes. As calpain activity is under strict control; fully active calpain may cleave a dozen of proteins; they are silenced in cells. Besides $\mathrm{Ca}^{2+}$ ion few partners are known as activators. $\mathrm{Ca}^{2+}$ ion is necessary for the formation of active site cleft in case of all calpain, but some of them need further process or interaction to reach the full activity [16]. However, these partners (e.g. phospholipids, kinases, some activator proteins $[163,164])$ cannot be easily utilized as external activators. In the endogenous inhibitor protein, calpastatin, there are three conserved subdomains, A, B and C. The A and C subdomains just potentiate the inhibitory effect assisting in the binding to calpain but have no inhibitory activity. It has been demonstrated that peptides corresponding to these subdomains, calpastatin A and C, enhanced the activity of calpain 1 and 2 [165]. Using these peptides as activators is hampered by their low internalization. This was improved by conjugation with cell-penetrating peptide (penetratin [166] and octaarginine [167]). All conjugates retained the 
calpain activator effect and conjugation with octaarginine boosted the calpain activity. That intensified the neuronal excitability in rat hippocampal slices.

Based on our knowledge, no systematic examination of small compounds as calpain activators have yet been performed, but some small molecules have been described as activators. A serine protease inhibitor, ethyl N-allyl-N-[(E)-2-methyl-3-[4-(4-amidinophenoxycarbonyl)phenyl]propenoyl]aminoacetate methanesulfonate (ONO-3403) enhanced calpain activity and had cytotoxicity on NIH3T3 cells [168]. A local anesthetic agent dibucain may also activate calpain in platelet and causes apoptosis [169]. Two cannabinoids, $\Delta^{9}$-tetrahydricannabinol and cannabidiol showed activating effect on calpain 1 enzyme [170]. As in this study four different derivatives were characterized, from the structural differences between active and inactive forms some SAR was identified.

In case of LGMD2A, gene therapy was tested transferring calpain 3 gene into muscle cells using adeno-associated virus vector by intramuscular injection [171]. The gene was stably expressed in muscle cells with proper protease activity and without any toxicity. Unfortunately this construct caused dose-dependent mortality after intravenous injection [172]. In the heart large areas of fibrosis were found which could be in accordance with the unregulated activity of calpain3. Modification of the vector, inhibited expression of calpain 3 in cardiovascular tissues, eliminated the cardiotoxicity and preserved its in vivo activity. Although increasing calpain activity may be a promising strategy, it has several drawbacks. As the general calpain inhibition may not result in serious side effect, in case of activators this may be more harmful.

\section{Conclusions}

Calpain enzymes play critical roles in several physiological processes, like cell motility, signal transduction, cell differentiation and memory formation. In some cases, they have protecting function (e.g. calpain 8 and 9 in the gastric mucosa). Their importance means that 
alteration in their functions, over- or underactivity, are involved in the development of several diseases (e.g. neurodegradations, traumatic injury caused cell-death, tumour cell survival, metathesis). Thus they are very promising therapeutic targets. In the development of their inhibitors or activators different drug discovery strategies can be used. Dozens of different inhibitors are described, therefore many SAR data are available. These data can be used to improve better and more selective inhibitors. Systematic chemical modification is commonly utilized to refine inhibitor properties. Delivery or targeting well-known inhibitors is another option. Finally, some examples highlighted the usefulness of molecular docking process. Albeit inhibitor design attracts more interest, development of activators may also be very attractive. This area is poorly examined, there was no systematic study performed to get SAR data, possibly because it is more challenging than the development of inhibitors. The examples of successful application of calpain inhibitors in in vivo models demonstrate that these researches remain hot topics in drug discovery.

\section{Expert opinion}

Calpain enzymes are a large family of intracellular cysteine proteases. They are involved in several pathological conditions with their over- or under-activation. This makes them very interesting and promising therapeutic targets. The main challenges in drug discovery in connection with them are a) our knowledge about their functions mainly restricted to the firstly described calpain 1 and 2, thus the other members of the family are poorly examined; b) they have very similar active site clefts not only with each other, but with other cysteine proteases as well.

It has been proven that in many cases the inhibition of calpain activity could reduce or reverse the pathological conditions. Therefor the development of calpain inhibitors is hot research topic. In the first studies known cysteine protease inhibitors were chemically modified to achieve calpain selective inhibitor activity. This strategy, the chemical modification of calpain 
inhibitors to cover more different chemical structures, was then used in many studies and resulted in very good, selective and/or active inhibitors. As our knowledge increased about the 3D structure of calpains and inhibitor bound calpains, these data were used for molecular docking to speed up the discovery of more diverse chemical space. Combination of these strategies may produce improved drug-like inhibitors. The third strategy applied on this field is the conjugation of efficient inhibitors with molecules that can increase pharmacological properties, stability, targeted localisation, increased cellular-uptake, in vitro and in vivo stability. For this, a strong requirement is that these attached moieties do not alter the inhibitory properties, just strengthen the weak features of inhibitors.

The challenges in the inhibitor design are to improve the specificity against other cysteine proteases or to reach isoform selectivity. The high similarity in the substrate-binding site does not allow the use of very diverse chemical structures, and thus substrate-like inhibitors rarely can distinguish these active sites. The specificity may increase using longer inhibitors that can bind not only to $S$ but $S$ ' site in the cleft. These types of inhibitors have not been fully examined, therefore further possibility remains for this unutilised potential. Albeit some allosteric inhibitors for calpain 1 are described, this area also has potential in the future to find better inhibitors.

Use of activator molecules may be a promising strategy to compensate pathological symptoms caused by low calpain activity. Thus, development of activators can be an attractive therapeutic target, but only few compounds have been described and they were poorly characterised. Their main problem is that their usage needs very cautious approach, because uncontrolled calpain activation may cause more serious side effects.

In conclusion, calpain modulator molecules, inhibitors or activators, are interesting targets of drug discovery. There are many promising examples about their usage and good effect in 
different pathological conditions. The uncovered or rarely researched areas on this field also increase their potential.

\section{Declaration of interest}

The authors have no other relevant affiliations or financial involvement with any organization or entity with a financial interest in or financial conflict with the subject matter or materials discussed in the manuscript apart from those disclosed.

\section{Reviewer Disclosures}

Peer reviewers on this manuscript have no relevant financial or other relationships to disclose.

\section{References}

Papers of special note have been highlighted as either of interest $(*)$ or of high interest $(* *)$ to readers.

[1] Guroff G. A neutral, Calcium-activated proteinase from the soluble fraction of rat brain. J Biol Chem. 1964;239:149-155.

[2] Cong J, Goll DE, Peterson AM, et al. The role of autolysis in activity of the Ca2+dependent proteinases (mu-calpain and m-calpain). J. Biol. Chem. 1989;264:1009610103.

[3] YoshimuraS N, Kikuchi T, Sasakis T, et al. Two distinct Ca2+ proteases (calpain I and calpain II) purified concurrently by the same method from rat kidney. J. Biol. Chem. $1983 ; 258: 8883-8889$.

[4] Goll DE, Thompson VF, Li H, et al. The calpain system. Physiol. Rev. 2003;83:731801.

[5] Inomata M, Nomoto M, Hayashi M, et al. Comparison of low and high calcium requiring forms of the calcium-activated neutral protease (CANP) from rabbit skeletal 
muscle. J Biochem. 1984;95:1661-1670.

[6] Sorimachi H, Hata S, Ono Y. Expanding members and roles of the calpain superfamily and their genetically modified animals. Exp Anim. 2010;59:549-566.

[7] Sorimachi H, Hata S, Ono Y. Calpain chronicle--an enzyme family under multidisciplinary characterization. Proc Jpn Acad Ser B Phys Biol Sci. 2011;87:287327.

[8] Hosfield C, Elce J, Davies P, et al. Crystal structure of calpain reveals the structural basis for $\mathrm{Ca}(2+)$-dependent protease activity and a novel mode of enzyme activation. EMBO J. 1999;18:6880-6889.

[9] Hanna R, Campbell R, Davies P. Calcium-bound structure of calpain and its mechanism of inhibition by calpastatin. Nature. 2008;456:409-412.

** This is papers described the 3D structure of activated and calpastatin bound calpain 2.

[10] Campbell RL, Davies PL. Structure-function relationships in calpains. Biochem. J. $2012 ; 447: 335-351$.

** In this paper the structural elements of calpains are discussed.

[11] Moldoveanu T, Gehring K, Green DR. Concerted multi-pronged attack by calpastatin to occlude the catalytic cleft of heterodimeric calpains. Nature. $2008 ; 456: 404-408$.

** In this paper the 3D structure of activated and calpastatin bound calpain 2 is given.

[12] Chai HH, Lim D, Lee SH, et al. Homology modeling study of bovine $\mu$-Calpain inhibitor-binding domains. Int. J. Mol. Sci. 2014;15:7897-7938. 
[13] Liang Z, Demko V, Wilson R, et al. The catalytic domain CysPc of the DEK1 calpain is functionally conserved in land plants. Plant J. 2013;75:742-754.

[14] P. Zimmerman, Landin Boring, Jhang U-J. The Calpain Small Subunit Gene Is Essential: Its Inactivation Results in Embryonic Lethality. IUBMB Life (International Union Biochem. Mol. Biol. Life). 2000;50:63-68.

[15] Murachi T, Tanaka K, Hatanaka M, et al. Intracellular Ca2+-dependent protease (CALPAIN) and its high-molecular-weight endogenous inhibitor (CALPASTATIN). Adv. Enzyme Regul. 1981;19:407-424.

[16] Laszlo K, Yunchao S. The Critical Role of Calpain in Cell Proliferation. J. Biomol. Res. Ther. 2014;03:112.

[17] Glading A, Lauffenburger DA, Wells A. Cutting to the chase: Calpain proteases in cell motility. Trends Cell Biol. 2002;12:46-54.

[18] Mendoza P, Silva P, Díaz J, et al. Calpain2 mediates Rab5-driven focal adhesion disassembly and cell migration. Cell Adh Migr. 2018;12:185-194.

[19] Glading A, Chang P, Lauffenburger D, et al. Epidermal growth factor receptor activation of calpain is required for fibroblast motility and occurs via an ERK/MAP kinase signaling pathway. J Biol Chem. 2000;275:2390-2398.

[20] Glading A, Überall F, Keyse SM, et al. Membrane Proximal ERK Signaling Is Required for M-calpain Activation Downstream of Epidermal Growth Factor Receptor Signaling. J. Biol. Chem. 2001;276:23341-23348.

[21] Carillo S, Pariat M, Steff AM, et al. Differential sensitivity of FOS and JUN family members to calpains. Oncogene. 1994;9:1679-1689.

[22] Choi YH, Lee SJ, Nguyen PM, et al. Regulation of cyclin D1 by calpain protease. J. 
Biol. Chem. 1997;272:28479-28484.

[23] Zhang W, Lu Q, Xie ZJ, et al. Inhibition of the growth of WI-38 fibroblasts by benzyloxycarbonyl-Leu-Leu-Tyr diazomethyl ketone: Evidence that cleavage of p53 by a calpain-like protease is necessary for G1 to S-phase transition. Oncogene. $1997 ; 14: 255-263$.

[24] Carragher NO, Westhoff MA, Riley D, et al. v-Src-Induced Modulation of the CalpainCalpastatin Proteolytic System Regulates Transformation. Mol. Cell. Biol. 2002;22:257-269.

[25] Santos DM, Xavier JM, Morgado AL, et al. Distinct regulatory functions of calpain 1 and 2 during neural stem cell self-renewal and differentiation. PLoS One. 2012;7.

[26] Shu Y, Xiang M, Zhang P, et al. Wnt-5a promotes neural development and differentiation by regulating CDK5 via Ca 2+/Calpain Pathway. Cell. Physiol. Biochem. 2019;51:2604-2615.

[27] Baudry M, Bi X. Calpain-1 and Calpain-2: The Yin and Yang of Synaptic Plasticity and Neurodegeneration. Trends Neurosci. 2016;39:235-245.

[28] Baudry M. Calpain-1 and Calpain-2 in the Brain: Dr. Jekill and Mr Hyde? Curr. Neuropharmacol. 2019;17:823-829.

\section{* This review summarised the roles and differences of calpain 1 and 2 functions in neurvous system.}

[29] Su Y, Cui Z, Li Z, et al. Calpain-2 regulation of VEGF-mediated angiogenesis. FASEB J. 2006;20:1443-1451

[30] Zhang Y, Liu NM, Wang Y, et al. Endothelial cell calpain as a critical modulator of angiogenesis. Biochim. Biophys. Acta - Mol. Basis Dis. 2017;1863:1326-1335. 


\section{* This review summarised the roles of calpains in angiogenesis.}

[31] Nassar D, Letavernier E, Baud L, et al. Calpain activity is essential in skin wound healing and contributes to scar formation. PLoS One. 2012;7:e37084.

[32] Arthur JSC, Elce JS, Hegadorn C, et al. Disruption of the Murine Calpain Small Subunit Gene, Capn4: Calpain Is Essential for Embryonic Development but Not for Cell Growth and Division. Mol. Cell. Biol. 2000;20:4474-4481.

[33] Bodnar RJ, Yates CC, Rodgers ME, et al. IP-10 induces dissociation of newly formed blood vessels. J. Cell Sci. 2009;122:2064-2077.

[34] Dutt P, Croall DE, Arthur JSC, et al. m-Calpain is required for preimplantation embryonic development in mice. BMC Dev. Biol. 2006;6:3.

[35] Takano J, Mihira N, Fujioka R, et al. Vital Role of the Calpain-Calpastatin System for Placental-Integrity-Dependent Embryonic Survival. Mol. Cell. Biol. 2011;31:40974106.

[36] Azam M, Andrabi SS, Sahr KE, et al. Disruption of the Mouse mu-Calpain Gene Reveals an Essential Role in Platelet Function. Mol. Cell. Biol. 2001;21:2213-2220.

[37] Araujo H, Julio A, Cardoso M. Translating genetic, biochemical and structural information to the calpain view of development. Mech. Dev. 2018;154:240-250.

\section{* This review summarised the roles of calpains in development.}

[38] Välimäki E, Cypryk W, Virkanen J, et al. Calpain Activity Is Essential for ATP-Driven Unconventional Vesicle-Mediated Protein Secretion and Inflammasome Activation in Human Macrophages. J. Immunol. 2016;197:3315-3325.

[39] Zhang Y, Rong H, Zhang FX, et al. A Membrane Potential- and Calpain-Dependent 
Reversal of Caspase-1 Inhibition Regulates Canonical NLRP3 Inflammasome. Cell Rep. 2018;24:2356-2369.e5.

[40] Davis MA, Fairgrieve MR, Den Hartigh A, et al. Calpain drives pyroptotic vimentin cleavage, intermediate filament loss, and cell rupture that mediates immunostimulation. Proc. Natl. Acad. Sci. U. S. A. 2019;116:5061-5070.

[41] Mikosik A, Jasiulewicz A, Daca A, et al. Roles of calpain-calpastatin system (CCS) in human T cell activation. Oncotarget. 2016;7:76479-76495.

[42] Ono Y, Ojima K, Shinkai-Ouchi F, et al. An eccentric calpain, CAPN3/p94/calpain-3. Biochimie. 2016;122:169-187.

[43] Ye Q, Campbell RL, Davies PL. Structures of human calpain-3 protease core with and without bound inhibitor reveal mechanisms of calpain activation. J. Biol. Chem. 2018;293:4056-4070.

[44] Mahajan VB, Skeie JM, Bassuk AG, et al. Calpain-5 Mutations Cause Autoimmune Uveitis, Retinal Neovascularization, and Photoreceptor Degeneration. PLoS Genet. $2012 ; 8$

[45] Wang Y, Li H, Zang S, et al. Photoreceptor cell-derived CAPN5 regulates retinal pigment epithelium cell proliferation through direct regulation of SLIT2 cleavage. Investig. Ophthalmol. Vis. Sci. 2018;59:1810-1821.

[46] Hata S, Abe M, Suzuki H, et al. Calpain 8/nCL-2 and Calpain 9/nCL-4 constitute an active protease complex, G-Calpain, involved in gastric mucosal defense. PLoS Genet. 2010;6:1-14.

[47] Pánico P, Salazar AM, Burns AL, et al. Role of calpain-10 in the development of diabetes mellitus and its complications. Arch. Med. Res. 2014;45:103-115. 
[48] Ono Y, Saido TC, Sorimachi H. Calpain research for drug discovery: Challenges and potential. Nat. Rev. Drug Discov. 2016;15:854-876.

[49] Momeni HR. Role of calpain in apoptosis. Cell J. 2011;13:65-72.

[50] Smith MA, Schnellmann RG. Calpains, mitochondria, and apoptosis. Cardiovasc. Res. 2012;96:32-37.

[51] Mahaman YAR, Huang F, Kessete Afewerky H, et al. Involvement of calpain in the neuropathogenesis of Alzheimer's disease. Med. Res. Rev. 2019;39:608-630.

** In this review pathomechanism of calpain action in Alzheimer's disease is described.

[52] Miyazaki T, Miyazaki A. Dysregulation of calpain proteolytic systems underlies degenerative vascular disorders. J. Atheroscler. Thromb. 2018;25:1-15.

[53] Huang J, Zhu X. The molecular mechanisms of calpains action on skeletal muscle atrophy. Physiol. Res. 2016;65:547-560.

[54] Lee MS, Kwon YT, Li M, et al. Neurotoxicity induces cleavage of p35 to p25 by calpain. Nature. 2000;405:360-364.

[55] Wen Y, Yu WH, Maloney B, et al. Transcriptional Regulation of $\beta$-Secretase by p25/cdk5 Leads to Enhanced Amyloidogenic Processing. Neuron. 2008;57:680-690.

[56] Alberdi E, Sánchez-Gómez MV, Cavaliere F, et al. Amyloid $\beta$ oligomers induce Ca2+ dysregulation and neuronal death through activation of ionotropic glutamate receptors. Cell Calcium. 2010;47:264-272.

[57] Jin N, Yin X, Yu D, et al. Truncation and activation of GSK-3 $\beta$ by calpain I: A molecular mechanism links to tau hyperphosphorylation in Alzheimer's disease. Sci. Rep. 2015;5:Article number: 8187. 
[58] Paudel HK, LewS J, AliS Z, et al. Brain Proline-directed Protein Kinase Phosphorylates Tau on Sites That Are Abnormally Phosphorylated in Tau Associated with Alzheimer's Paired Helical Filaments* Brain proline-directed protein kinase (BPDK), which contains a catalytic subunit homologous t. J. Biol. Chem. $1993 ; 268: 23512-23518$.

[59] Hanger DP, Hughes K, Woodgett JR, et al. Glycogen synthase kinase-3 induces Alzheimer's disease-like phosphorylation of tau: Generation of paired helical filament epitopes and neuronal localisation of the kinase. Neurosci. Lett. 1992;147:58-62.

[60] Subramanian V, Uchida HA, Ijaz T, et al. Calpain inhibition attenuates angiotensin IIinduced abdominal aortic aneurysms and atherosclerosis in low-density lipoprotein receptor-deficient mice. J. Cardiovasc. Pharmacol. 2012;59:66-76.

[61] Howatt DA, Balakrishnan A, Moorleghen JJ, et al. Leukocyte calpain deficiency reduces Angiotensin II-induced inflammation and atherosclerosis but not abdominal aortic aneurysms in mice. Arterioscler. Thromb. Vasc. Biol. 2016;36:835-845.

[62] Miyazaki T, Taketomi Y, Takimoto M, et al. m-calpain induction in vascular endothelial cells on human and mouse atheromas and its roles in VE-cadherin disorganization and atherosclerosis. Circulation. 2011;124:2522-2532.

[63] Su W, Kowalczyk AP. The VE-cadherin cytoplasmic domain undergoes proteolytic processing during endocytosis. Mol. Biol. Cell. 2017;28:76-84.

[64] Miyazaki T, Tonami K, Hata S, et al. Calpain-6 confers atherogenicity to macrophages by dysregulating pre-mRNA splicing. J. Clin. Invest. 2016;126:3417-3432.

[65] Cao T, Fan S, Zheng D, et al. Increased calpain-1 in mitochondria induces dilated heart failure in mice: role of mitochondrial superoxide anion. Basic Res. Cardiol. 2019;114. 
[66] Wells GJ, Bihovsky R. Calpain inhibitors as potential treatment for stroke and other neurodegenerative diseases: recent trends and developments. Exp. Opin. Ther. Patents. $1998 ; 8: 1707-1727$.

[67] Liu S, Yin F, Zhang J, et al. The role of calpains in traumatic brain injury. Brain Inj. 2014;28:133-137.

[68] Wang Y, Bi X, Baudry M. Calpain-2 as a therapeutic target for acute neuronal injury. Expert Opin. Ther. Targets. 2018;22:19-29.

[69] Saatman KE, Bozyczko-Coyne D, Marcy V, et al. Prolonged calpain-mediated spectrin breakdown occurs regionally following experimental brain injury in the rat. J. Neuropathol. Exp. Neurol. 1996;55:850-860.

[70] Zhang Z, Larner SF, Liu MC, et al. Multiple alphaII-spectrin breakdown products distinguish calpain and caspase dominated necrotic and apoptotic cell death pathways. Apoptosis. 2009;14:1289-1298.

[71] Wang Y, Liu Y, Lopez D, et al. Protection against TBI-Induced Neuronal Death with Post-Treatment with a Selective Calpain-2 Inhibitor in Mice. J. Neurotrauma. 2018;35:105-117.

[72] Storr SJ, Carragher NO, Frame MC, et al. The calpain system and cancer. Nat. Rev. Cancer. 2011;11:364-374.

* This review organised the knowledge of the activity and action of calpains in cancer.

[73] Tan Y, Wu C, De Veyra T, et al. Ubiquitous calpains promote both apoptosis and survival signals in response to different cell death stimuli. J. Biol. Chem. 2006;281:17689-17698.

[74] Conacci-Sorrell M, Ngouenet C, Anderson S, et al. Stress-induced cleavage of Myc 
promotes cancer cell survival. Genes Dev. 2014;28:689-707.

[75] Gafni J, Cong X, Chen SF, et al. Calpain-1 cleaves and activates caspase-7. J. Biol. Chem. 2009;284:25441-25449.

[76] Gil-Parrado S, Fernández-Montalván A, Assfalg-Machleidt I, et al. Ionomycinactivated calpain triggers apoptosis. A probable role for Bcl-2 family members. J. Biol. Chem. 2002;277:27217-27226.

[77] Chen J, Wu Y, Zhang L, et al. Evidence for calpains in cancer metastasis. J. Cell. Physiol. 2019;234:8233-8240.

[78] Cheng F, Mohanmed MM, Li Z, et al. Capn4 promotes colorectal cancer cell proliferation by increasing MAPK7 through activation of the Wnt/ $\beta$-Catenin pathway. Exp. Cell Res. 2018;363:235-242.

[79] Wang E, Wang D, Li B, et al. Capn4 promotes epithelial-mesenchymal transition in human melanoma cells through activation of the Wnt/ $\beta$-catenin pathway. Oncol. Rep. 2017;37:379-387.

[80] Chen Y, Wang G, Wang Y, et al. Capn4 regulates migration and invasion of ovarian carcinoma cells via targeting osteopontin-mediated PI3K/AKT signaling pathway. Oncol. Lett. 2019;17:564-570.

[81] Peng P, Wu W, Zhao J, et al. Decreased expression of Calpain-9 predicts unfavorable prognosis in patients with gastric cancer. Sci. Rep. 2016;6:29604.

[82] Zheng X, Zhou A-X, Rouhi P, et al. Hypoxia-induced and calpain-dependent cleavage of filamin A regulates the hypoxic response. Proc. Natl. Acad. Sci. 2014;111:25602565.

[83] Lasa-Elgarresta J, Mosqueira-Martín L, Naldaiz-Gastesi N, et al. Calcium Mechanisms 
in Limb-Girdle Muscular Dystrophy with CAPN3 Mutations. Int. J. Mol. Sci. 2019;20:E4548.

[84] Zhang Y, Li Q, Youn JY, et al. Protein phosphotyrosine phosphatase 1B (PTP1B) in calpaindependent feedback regulation of vascular endothelial growth factor receptor (VEGFR2) in endothelial cells: Implications in VEGF-dependent angiogenesis and diabetic wound healing. J. Biol. Chem. 2017;292:407-417.

[85] Hatta T, Iemura S ichiro, Ohishi T, et al. Calpain-10 regulates actin dynamics by proteolysis of microtubule-associated protein 1B. Sci. Rep. 2018;8.

[86] Zhang G, Fang T, Chang M, et al. Calpain 2 knockdown promotes cell apoptosis and restores gefitinib sensitivity through epidermal growth factor receptor/protein kinase B/survivin signaling. Oncol. Rep. 2018;40:1937-1946.

[87] MacLeod JA, Gao Y, Hall C, et al. Genetic disruption of calpain-1 and calpain-2 attenuates tumorigenesis in mouse models of HER2+ breast cancer and sensitizes cancer cells to doxorubicin and lapatinib. Oncotarget. 2018;9:33382-33395.

[88] Pin F, Minero VG, Penna F, et al. Interference with Ca 2+-dependent proteolysis does not alter the course of muscle wasting in experimental cancer cachexia. Front. Physiol. $2017 ; 8: 213$

[89] Maki M, Bagci H, Hamaguchi K, et al. Inhibition of calpain by a synthetic oligopeptide corresponding to an exon of the human calpastatin gene. J. Biol. Chem. 1989;264:18866-18869.

[90] Sher JH, Stracher A, Shafiq SA, et al. Successful treatment of murine muscular dystrophy with the proteinase inhibitor leupeptin. Proc. Natl. Acad. Sci. 1981;78:77427744. 
[91] Mehdi S, Angelastro MR, Wiseman JS, et al. Inhibition of the proteolysis of rat erythrocyte membrane proteins by a synthetic inhibitor of calpain. Biochem. Biophys. Res. Commun. 1988;157:1117-1123.

[92] Donkor IO. Calpain inhibitors: A survey of compounds reported in the patent and scientific literature. Expert Opin. Ther. Pat. 2011;21:601-636.

[93] Donkor IO. An updated patent review of calpain inhibitors (2012-2014). Expert Opin. Ther. Pat. 2015;25:17-31.

\section{** The 92 and 93 papers give a very good overview of calpain inhibitors, which were described till 2014. Usefull informations are about the main structural elements of inhibitors.}

[94] Tompa P, Buzder-Lantos P, Tantos A, et al. On the sequential determinants of calpain cleavage. J. Biol. Chem. 2004;279:20775-20785.

[95] Cuerrier D, Moldoveanu T, Davies PL. Determination of peptide substrate specificity for $\mu$-calpain by a peptide library-based approach: The importance of primed side interactions. J. Biol. Chem. 2005;280:40632-40641.

$* *$ Amino acid preferences of $\mu$-calpain is described in this paper. This may help in the design of new inhibitors.

[96] Farkas A, Tompa P, Friedrich P. Revisiting ubiquity and tissue specificity of human calpains. J. Biol. Chem. 2003;384:945-949.

[97] Emori Y, Kawasaki H, Imajoh S, et al. All four repeating domains of the endogenous inhibitor for calcium-dependent protease independently retain inhibitory activity. Expression of the cDNA fragments in Escherichia coli. J. Biol. Chem. 1988;263:23642370. 
[98] Kiss R, Kovács D, Tompa P, et al. Local structural preferences of calpastatin, the intrinsically unstructured protein inhibitor of calpain. Biochemistry. 2008;47:69366945.

[99] Hanna RA, Garcia-Diaz BE, Davies PL. Calpastatin simultaneously binds four calpains with different kinetic constants. FEBS Lett. 2007;581:2894-2898.

[100] Alluri H, Grimsley M, Shaji CA, et al. Attenuation of blood-brain barrier breakdown and hyperpermeability by calpain inhibition. J. Biol. Chem. 2016;291:26958-26969.

[101] Lin XY, Chen SZ. Calpain inhibitors ameliorate muscle wasting in a cachectic mouse model bearing CT26 colorectal adenocarcinoma. Oncol. Rep. 2017;37:1601-1610.

[102] Wu HY, Tomizawa K, Matsushita M, et al. Poly-arginine-fused calpastatin peptide, a living cell membrane-permeable and specific inhibitor for calpain. Neurosci. Res. 2003;47:131-135.

[103] Gil-Parrado S, Assfalg-Machleidt I, Fiorino F, et al. Calpastatin exon 1B-derived peptide, a selective inhibitor of calpain: Enhancing cell permeability by conjugation with penetratin. Biol. Chem. 2003;384:395-402.

[104] Fiorino F, Gil-Parrado S, Assfalg-Machleidt I, et al. A new cell-permeable calpain inhibitor. J. Pept. Sci. 2007;13:70-73.

[105] Sengoku T, Bondada V, Hassane D, et al. Tat-calpastatin fusion proteins transduce primary rat cortical neurons but do not inhibit cellular calpain activity. Exp. Neurol. 2004;188:161-170.

[106] Popp O, Heidinger M, Ruiz-Heinrich L, et al. The calpastatin-derived calpain inhibitor CP1B reduces mRNA expression of matrix metalloproteinase- 2 and -9 and invasion by leukemic THP-1 cells. Biol. Chem. 2003;384:951-958. 
[107] Betts R, Weinsheimer S, Blouse GE, et al. Structural determinants of the calpain inhibitory activity of calpastatin peptide B27-WT. J. Biol. Chem. 2003;278:7800-7809.

[108] Betts R, Anagli J. The $\beta$ - and $\gamma$-CH2 of B27-WT's Leu1 1 and Ile18 Side Chains Play a Direct Role in Calpain Inhibition. Biochemistry. 2004;43:2596-2604.

[109] Pfizer J, Assfalg-Machleidt I, MacHleidt W, et al. Inhibition of human $\mu$-calpain by conformationally constrained calpastatin peptides. Biol. Chem. 2008;389:83-90.

[110] Anagli J, Han Y, Stewart L, et al. A novel calpastatin-based inhibitor improves postischemic neurological recovery. Biochem. Biophys. Res. Commun. 2009;385:9499.

[111] Jo H, Meinhardt N, Wu Y, et al. Development of $\alpha$-helical calpain probes by mimicking a natural protein-protein interaction. J. Am. Chem. Soc. 2012;134:1770417713.

[112] Low KE, Ler S, Chen KJ, et al. Rational Design of Calpain Inhibitors Based on Calpastatin Peptidomimetics. J. Med. Chem. 2016;59:5403-5415.

\section{**Good example how the solved structure of calpain 2 may promote the design of specific calpain inhibitors.}

[113] Zaretsky S, Scully CCG, Lough AJ, et al. Exocyclic control of turn induction in macrocyclic peptide scaffolds. Chem. - A Eur. J. 2013;19:17668-17672.

[114] Turk V, Stoka V, Vasiljeva O, et al. Cysteine cathepsins: From structure, function and regulation to new frontiers. Biochim. Biophys. Acta - Proteins Proteomics. 2012;1824:68-88.

[115] Iqbal M, Messina PA, Freed B, et al. Subsite requirements for peptide aldehyde inhibitors of human calpain I. Bioorganic Med. Chem. Lett. 1997;7:539-544. 
[116] Kwang SL, Seon HS, Yong HL, et al. Synthesis and biological evaluation of chromone carboxamides as calpain inhibitors. Bioorganic Med. Chem. Lett. 2005;15:2857-2860.

[117] Nam DH, Lee KS, Kim SH, et al. Design and synthesis of 4-quinolinone 2carboxamides as calpain inhibitors. Bioorganic Med. Chem. Lett. 2008;18:205-209.

[118] Zhang Y, Jung SY, Jin C, et al. Design and synthesis of 4-aryl-4-oxobutanoic acid amides as calpain inhibitors. Bioorganic Med. Chem. Lett. 2009;19:502-507.

[119] Jantos K, Kling A, Mack H, et al. Discovery of ABT-957: 1-Benzyl-5-oxopyrrolidine2-carboxamides as selective calpain inhibitors with enhanced metabolic stability. Bioorganic Med. Chem. Lett. 2019;29:1968-1973.

[120] Lubisch W, Möller A. Discovery of phenyl alanine derived ketoamides carrying benzoyl residues as novel calpain inhibitors. Bioorganic Med. Chem. Lett. 2002;12:1335-1338.

[121] Lubisch W, Beckenbach E, Bopp S, et al. Benzoylalanine-derived ketoamides carrying vinylbenzyl amino residues: Discovery of potent water-soluble calpain inhibitors with oral bioavailability. J. Med. Chem. 2003;46:2404-2412.

[122] Nikkel AL, Martino B, Markosyan S, et al. The novel calpain inhibitor A-705253 prevents stress-induced tau hyperphosphorylation in vitro and in vivo. Neuropharmacology. 2012;63:606-612.

[123] Granic I, Nyakas C, Luiten PGM, et al. Calpain inhibition prevents amyloid- $\beta$-induced neurodegeneration and associated behavioral dysfunction in rats. Neuropharmacology. 2010;59:334-342.

[124] Kling A, Jantos K, Mack H, et al. Discovery of Novel and Highly Selective Inhibitors of Calpain for the Treatment of Alzheimer's Disease: 2-(3-Phenyl-1H-pyrazol-1-yl)- 
nicotinamides. J. Med. Chem. 2017;60:7123-7138.

[125] Kling A, Jantos K, MacK H, et al. Mitigating the Metabolic Liability of Carbonyl Reduction: Novel Calpain Inhibitors with P1' Extension. ACS Med. Chem. Lett. 2018;9:221-226.

[126] Lon HK, Mendonca N, Goss S, et al. Pharmacokinetics, Safety, Tolerability, and Pharmacodynamics of Alicapistat, a Selective Inhibitor of Human Calpains 1 and 2 for the Treatment of Alzheimer Disease: An Overview of Phase 1 Studies. Clin. Pharmacol. Drug Dev. 2019;8:290-303.

[127] Lescop C, Herzner H, Siendt H, et al. Novel cell-penetrating $\alpha$-keto-amide calpain inhibitors as potential treatment for muscular dystrophy. Bioorganic Med. Chem. Lett. 2005;15:5176-5181.

[128] Weyermann P, Herzner H, Lescop C, et al. Synthesis and evaluation of calpain inhibitors carrying muscle cell targeting groups. Lett. Drug Des. Discov. 2006;3:152158.

[129] Saatman KE, Murai H, Bartus RT, et al. Calpain inhibitor AK295 attenuates motor and cognitive deficits following experimental brain injury in the rat. Proc. Natl. Acad. Sci. U. S. A. 1996;93:3428-3433.

[130] Ovat A, Li ZZ, Hampton CY, et al. Peptidyl $\alpha$-ketoamides with nucleobases, methylpiperazine, and dimethylaminoalkyl substituents as calpain inhibitors. J. Med. Chem. 2010;53:6326-6336.

[131] Li Z, Ortega-Vilain AC, Patil GS, et al. Novel peptidyl $\alpha$-keto amide inhibitors of calpains and other cysteine proteases. J. Med. Chem. 1996;39:4089-4098.

[132] Stracher A, Kesner L, Shulman A. Targeted delivery of pharmaceutical compounds. 
US8729024. 2007.

[133] Dugue R, Hassen GW, Shulman A, et al. Controlled cortical impact-induced neurodegeneration decreases after administration of the novel calpain-inhibitor Gabadur. Brain Res. Bull. 2018;142:368-373.

[134] Hassen GW, Kesner L, Stracher A, et al. Effects of Novel Calpain Inhibitors in Transgenic Animal Model of Parkinson’s disease/dementia with Lewy bodies. Sci. Rep. 2018;8:18083.

[135] Rasbach KA, Arrington DD, Odejinmi S, et al. Identification and optimization of a novel inhibitor of mitochondrial calpain 10. J. Med. Chem. 2008;52:181-188.

[136] Smith MA, McInnes C, Whitaker RM, et al. Calpain 10 homology modeling with CYGAK and increased lipophilicity leads to greater potency and efficacy in cells. ACS Chem. Biol. 2012;7:1410-1419.

[137] Jones MA, Morton JD, Coxon JM, et al. Synthesis, biological evaluation and molecular modelling of N-heterocyclic dipeptide aldehydes as selective calpain inhibitors. Bioorganic Med. Chem. 2008;16:6911-6923.

[138] Jones S, Jones M, McNabb S, et al. N-Heterocyclic Dipeptide Aldehyde Calpain Inhibitors. Protein Pept. Lett. 2009;16:1466-1472.

[139] Madala PK, Tyndall JDA, Nall T, et al. Update 1 of: Proteases universally recognize beta strands in their active sites. Chem. Rev. 2010;110:PR1-PR31.

[140] Cherney RJ, Wang L, Meyer DT, et al. Macrocyclic amino carboxylates as selective MMP-8 inhibitors. J. Med. Chem. 1998;41:1749-1751.

[141] Lamarre D, Anderson PC, Bailey M, et al. An NS3 protease inhibitor with antiviral effects in humans infected with hepatitis C virus. Nature. 2003;426:186-189. 
[142] Abell AD, Jones MA, Coxon JM, et al. Molecular modeling, synthesis, and biological evaluation of macrocyclic calpain inhibitors. Angew. Chemie - Int. Ed. 2009;48:14551458.

\section{* Good source of how to design macrocycle to mimic $\beta$-strand-like peptide-backbone conformation.}

[143] Chen H, Jiao W, Jones MA, et al. New tripeptide-based macrocyclic calpain inhibitors formed by n-alkylation of histidine. Chem. Biodivers. 2012;9:2473-2484.

[144] Jones SA, Neilsen PM, Siew L, et al. A template-based approach to inhibitors of calpain 2, 20 S proteasome, and HIV-1 protease. ChemMedChem. 2013;8:1918-1921.

[145] Powers JC, Boone R, Carroll DL, et al. Reaction of azapeptides with human leukocyte elastase and porcine pancreatic elastase. New inhibitors and active site titrants. J. Biol. Chem. 1984;259:4288-4294.

[146] Magrath J, Abeles RH. Cysteine Protease Inhibition by Azapeptide Esters. J. Med. Chem. 1992;35:4279-4283.

[147] Bánóczi Z, Tantos Á, Farkas A, et al. New m-calpain substrate-based azapeptide inhibitors. J. Pept. Sci. 2013;19:370-376.

[148] Hanada K, Tamai M, Yamagishi M, et al. Isolation and Characterization of E-64, a New Thiol Protease Inhibitor. Agric. Biol. Chem. 1978;42:523-528.

[149] Dókus LE, Menyhárd DK, Tantos Á, et al. Probing of primed and unprimed sites of calpains: Design, synthesis and evaluation of epoxysuccinyl-peptide derivatives as selective inhibitors. Eur. J. Med. Chem. 2014;82:274-280.

[150] Schiefer IT, Tapadar S, Litosh V, et al. Design, synthesis, and optimization of novel epoxide incorporating peptidomimetics as selective calpain inhibitors. J. Med. Chem. 
2013;56:6054-6068.

[151] Stuart BG, Coxon JM, Morton JD, et al. Molecular modeling: A search for a calpain inhibitor as a new treatment for cataractogenesis. J. Med. Chem. 2011;54:7503-7522.

[152] Muralidharan AR, Selvaraj C, Singh SK, et al. Structure-Based Virtual Screening and Biological Evaluation of a Calpain Inhibitor for Prevention of Selenite-Induced Cataractogenesis in an in Vitro System. J. Chem. Inf. Model. 2015;55:1686-1697.

\section{* This paper describes how structure-based virtual screening may promote the calpain inhibitor devlopment.}

[153] Muralidharan AR, Selvaraj C, Singh SK, et al. Virtual screening based on pharmacophoric features of known calpain inhibitors to identify potent inhibitors of calpain. Med. Chem. Res. 2014;23:2445-2455.

[154] Kalash L, Cresser-Brown J, Habchi J, et al. Structure-based design of allosteric calpain-1 inhibitors populating a novel bioactivity space. Eur. J. Med. Chem. 2018; 157:1264-1275.

\section{*This paper gives the first examples of allosteric calpain inhibitors.}

[155] Wang KKW, Nath R, Posner A, et al. An alpha-mercaptoacrylic acid derivative is a selective nonpeptide cell- permeable calpain inhibitor and is neuroprotective. Proc. Natl. Acad. Sci. U. S. A. 1996;93:6687-6692.

[156] Lin G Da, Chattopadhyay D, Maki M, et al. Crystal structure of calcium bound domain VI of calpain at $1.9 \AA$ resolution and its role in enzyme assembly, regulation, and inhibitor binding. Nat. Struct. Biol. 1997;4:539-547.

[157] Adams SE, Parr C, Miller DJ, et al. Potent inhibition of Ca2+-dependent activation of calpain-1 by novel mercaptoacrylates. Medchemcomm. 2012;3:566-570. 
[158] Adams SE, Rizkallah PJ, Miller DJ, et al. The structural basis of differential inhibition of human calpain by indole and phenyl $\alpha$-mercaptoacrylic acids. J. Struct. Biol. 2014;187:236-241.

[159] Adams SE, Robinson EJ, Miller DJ, et al. Conformationally restricted calpain inhibitors. Chem. Sci. 2015;6:6865-6871.

[160] Low KE, Karunan Partha S, Davies PL, et al. Allosteric inhibitors of calpains: Reevaluating inhibition by PD150606 and LSEAL. Biochim. Biophys. Acta - Gen. Subj. 2014;1840:3367-3373.

[161] Baell JB, Holloway GA. New substructure filters for removal of pan assay interference compounds (PAINS) from screening libraries and for their exclusion in bioassays. J. Med. Chem. 2010;53:2719-2740.

[162] Tong-Jun L. Inhibition of calpain reduces allergic inflammation. US20090297510A1; 2009.

[163] Melloni E, Michetti M, Salamino F, et al. Molecular and functional properties of a calpain activator protein specific for mu-isoforms. J. Biol. Chem. 1998;273:1282712831.

[164] Michetti M, Viotti PL, Melloni E, et al. Mechanism of action of the calpain activator protein in rat skeletal muscle. Eur. J. Biochem. 1991;202:1177-1180.

[165] Tompa P, Mucsi Z, Orosz G, et al. Calpastatin subdomains A and C are activators of calpain. J. Biol. Chem. 2002;277:9022-9026.

[166] Bánoczi Z, Tantos Á, Farkas A, et al. Synthesis of cell-penetrating conjugates of calpain activator peptides. Bioconjug. Chem. 2007;18:130-137.

[167] Világi I, Kiss DS, Farkas A, et al. Synthetic calpain activator boosts neuronal 
excitability without extra Ca2+. Mol. Cell. Neurosci. 2008;38:629-636.

[168] Hiwasa T. Induction of apoptosis by a calpain stimulator, ONO-3403. Apoptosis. $1996 ; 1: 75-75$.

[169] Zhang W, Liu J, Sun R, et al. Calpain activator dibucaine induces platelet apoptosis. Int. J. Mol. Sci. 2011;12:2125-2137.

[170] Takeda S, Watanabe K, Aramaki H. Phytocannabinoids, $\Delta^{9}$-tetrahydrocannabinol and cannabidiol, as human calpain-1 (CAPN1) activators. Fundam. Toxicol. Sci. 2017;4:101-103.

[171] Bartoli M, Roudaut C, Martin S, et al. Safety and efficacy of AAV-mediated calpain 3 gene transfer in a mouse model of limb-girdle muscular dystrophy Type 2A. Mol. Ther. 2006;13:250-259.

[172] Roudaut C, Le Roy F, Suel L, et al. Restriction of calpain3 expression to the skeletal muscle prevents cardiac toxicity and corrects pathology in a murine model of limbgirdle muscular dystrophy. Circulation. 2013;128:1094-1104.

[173] Ozaki T, Ishiguro S ichi, Hirano S, et al. Inhibitory Peptide of Mitochondrial $\mu$-Calpain Protects against Photoreceptor Degeneration in Rhodopsin Transgenic S334ter and P23H Rats. PLoS One. 2013;8.

[174] Parkes C, Kembhavi AA, Barrett AJ. Calpain inhibition by peptide epoxides. Biochem. J. 1985;230:509-516.

[175] Salamino F, De Tullio R, Michetti M, et al. Modulation of calpastatin specificity in rat tissues by reversible phosphorylation and dephosphorylation. Biochem. Biophys. Res. Commun. 1994;199:1326-1332. 
Table 1 Members of calpain enzyme family

\begin{tabular}{|c|c|c|c|}
\hline Enzyme & Expression & Protease activity & PEF $^{*}$ \\
\hline calpain 1 & ubiquitous & + & + \\
\hline calpain 2 & ubiquitous & + & + \\
\hline calpain 3 & $\begin{array}{c}\text { skeletal muscle, lens, } \\
\text { retina }\end{array}$ & + & + \\
\hline calpain 5 & ubiquitous & + & - \\
\hline calpain 6 & $\begin{array}{c}\text { embryonic muscles, } \\
\text { placenta }\end{array}$ & - & - \\
\hline calpain 7 & ubiquitous & + & - \\
\hline calpain 8 & stomach & + & + \\
\hline calpain 9 & digestive track & + & + \\
\hline calpain 10 & ubiquitous & + & + \\
\hline calpain 11 & testis & n.d. & + \\
\hline calpain 12 & hair follicle & n.d. & + \\
\hline calpain 13 & ubiquitous & n.d. & + \\
\hline calpain 14 & ubiquitous & + & - \\
\hline calpain 15 & ubiquitous & - & - \\
\hline calpain 16 & ubiquitous & - & \\
\hline
\end{tabular}

*PEF: penta-EF-hand domain; n.d. no data 
Table 2 Role and activity of calpain isoforms in different disorders

\begin{tabular}{|c|l|c|}
\hline Enzyme & \multicolumn{1}{|c|}{ Disorder } & Activity \\
\hline calpain 1 & myocardial injury and heart failure & + \\
& angiotensin II induced atherosclerosis & + \\
& Alzheimer disease & + \\
\hline \multirow{3}{*}{ tumorigenesis } & $+/-$ \\
\hline \multirow{2}{*}{ calpain 2 } & angiotensin II induced atherosclerosis & + \\
& VE-cadherin causing barrier dysfunction between endothelial cells & + \\
& Alzheimer disease & + \\
& wound healing in diabetes & - \\
\hline calpain 4 & tumorigenesis & $+/-$ \\
\hline calpain 6 & atherosclerosis & - \\
\hline calpain 8 8 & gastric mucosal protection (in G-calpain complex form) & + \\
\hline calpain 9 & & + \\
\hline
\end{tabular}


Table 3 Potency of some calpain inhibitors

\begin{tabular}{|c|c|c|c|c|c|}
\hline \multirow[t]{2}{*}{ Inhibitor } & \multicolumn{2}{|c|}{${ }^{\mathrm{a}} \mathrm{K}_{\mathrm{i}}(\boldsymbol{\mu M})$ or ${ }^{\mathrm{b}} \mathrm{IC}_{50}(\boldsymbol{M M})$} & \multirow{2}{*}{$\begin{array}{l}\text { Calpain } \\
\text { specific }\end{array}$} & \multirow{2}{*}{$\begin{array}{l}\text { Disease/ } \\
\text { phenomenon }\end{array}$} & \multirow[t]{2}{*}{ Model } \\
\hline & Calpain 1 & Calpain 2 & & & \\
\hline PD150606 [155] & $0.21^{\mathrm{a}}$ & $0.37^{\mathrm{a}}$ & + & $\begin{array}{l}\text { Retinitis } \\
\text { pigmentosa } \\
{[173]}\end{array}$ & animal, rat \\
\hline PD151746 [155] & $0.26^{\mathrm{a}}$ & $5.33^{\mathrm{a}}$ & + & & animal \\
\hline E64 [174] & \multicolumn{2}{|l|}{$3.96^{\mathrm{a}, \mathrm{c}}$} & - & & \\
\hline $\begin{array}{l}\mathrm{Ac} \text {-TSLAglySPPPS- } \mathrm{NH}_{2} \\
\text { [147] }\end{array}$ & $14.0^{\mathrm{a}}$ & $3.5^{\mathrm{a}}$ & n.d. & & \\
\hline $\begin{array}{l}\mathrm{NH}_{2} \text {-TPL(D-Eps)TPPPS- } \mathrm{NH}_{2} \\
\text { [149] }\end{array}$ & $>50^{\mathrm{a}}$ & $4.24^{\mathrm{a}}$ & + & & \\
\hline $\begin{array}{l}\mathrm{NH}_{2} \text {-TWL(L-Eps)SPPPS- } \mathrm{NH}_{2} \\
\text { [149] }\end{array}$ & $17.14^{\mathrm{a}}$ & $4.05^{\mathrm{a}}$ & - & & \\
\hline $\begin{array}{l}\text { Calpastatin I. (rat kidney) } \\
{[175]}\end{array}$ & $0.027^{\mathrm{a}}$ & $0.092^{\mathrm{a}}$ & + & & \\
\hline $\begin{array}{l}\text { Alicapistat } \\
\text { (ABT-957) [119] }\end{array}$ & $0.13^{\mathrm{a}}$ & n.d. & + & $\begin{array}{l}\text { Alzheimer } \\
\text { disease [126] }\end{array}$ & $\begin{array}{l}\text { clinical } \\
\text { phase1[126] }\end{array}$ \\
\hline $\begin{array}{l}\text { DPMSSTYIEELGKREVTIPP } \\
\text { KYRELLA [89] }\end{array}$ & $0.1^{\mathrm{b}}$ & $0.02^{b}$ & + & & \\
\hline
\end{tabular}

n.d. no data

A) Structure of a classical calpain

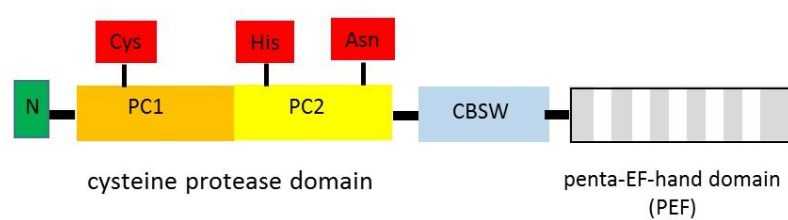

Structure of a non-classical calpain

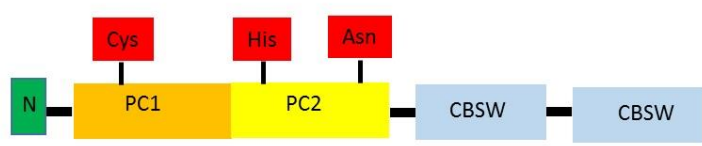

cysteine protease domain
B)

\begin{tabular}{|l|c|c|c|c|c|}
\hline & A B C & A B C & A B C & A B C \\
\hline & I & II & III & IV \\
\hline \multicolumn{4}{|c|}{} \\
\hline
\end{tabular}

*subdomain A: \$12GKSGMDAALDDLIDTLGG $^{31}$

* subdomain B: $\mathrm{M}^{51}$ SSTYIEELGKREVTIPPKYRELLAKK ${ }^{77}$

*subdomian C: S $^{86} \mathrm{KPIGPDDAIDALSSDFTS}{ }^{105}$

Figure 1 Schematic structure of A) classical and non-classical calpains and B) calpastatin molecule. N: N region; PC1: protease core 1 domain; PC2: protease core 2 domain; CBSW: calpain-type beta-sandwich domain. In case of calpastatin only the domain I-IV have inhibtory activity and each can binds to a calpain molecule. *The sequences of subdomains in human calpastatin domain I. 
A)

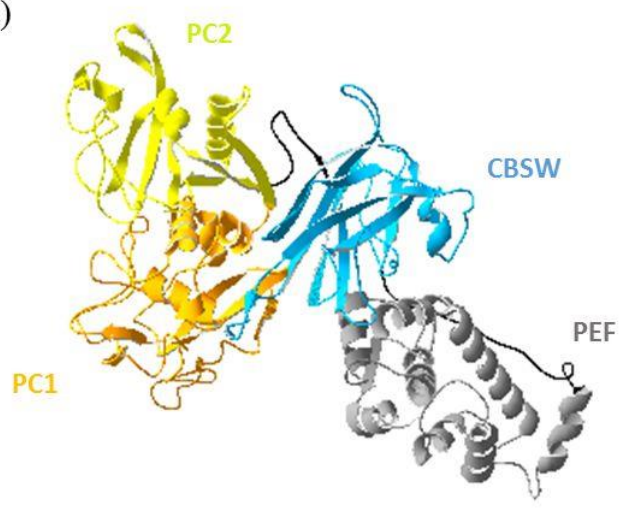

B)

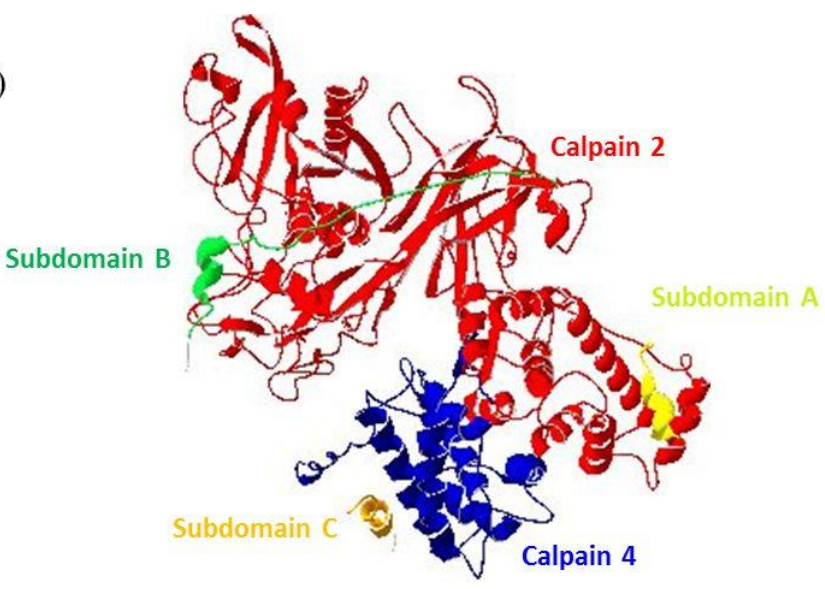

Figure 2 3D structure of the complex between calcium-bound calpain-2 and calpastatin. A) the domain structure of calpain 2, B) the structure of complex between the activated calpain 2- calpain 4 and calpastatin first inhibitory domain. PDB code 3DF0 [11] Images was created with Swiss-Pdb Viewer.

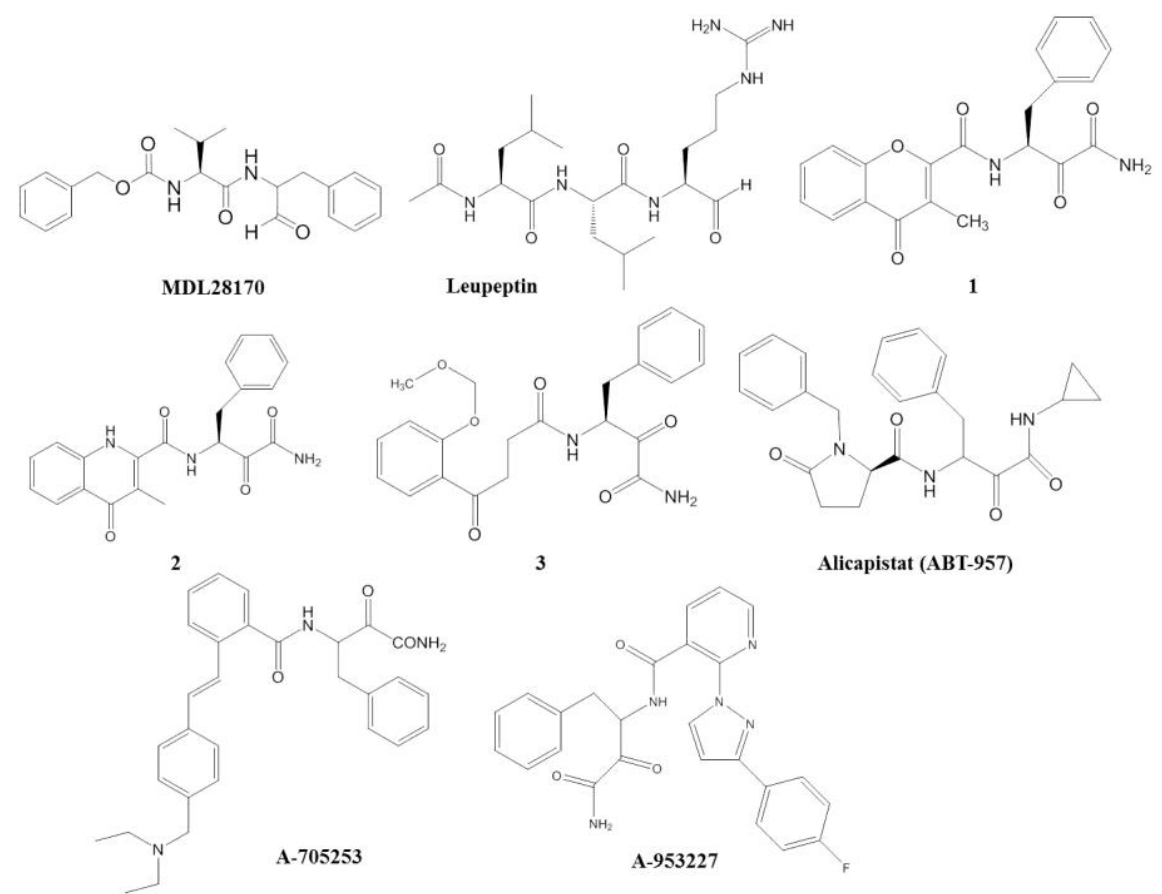

Figure 3 structure of substrate based peptide and peptidomimetic calpain inhibitors. 


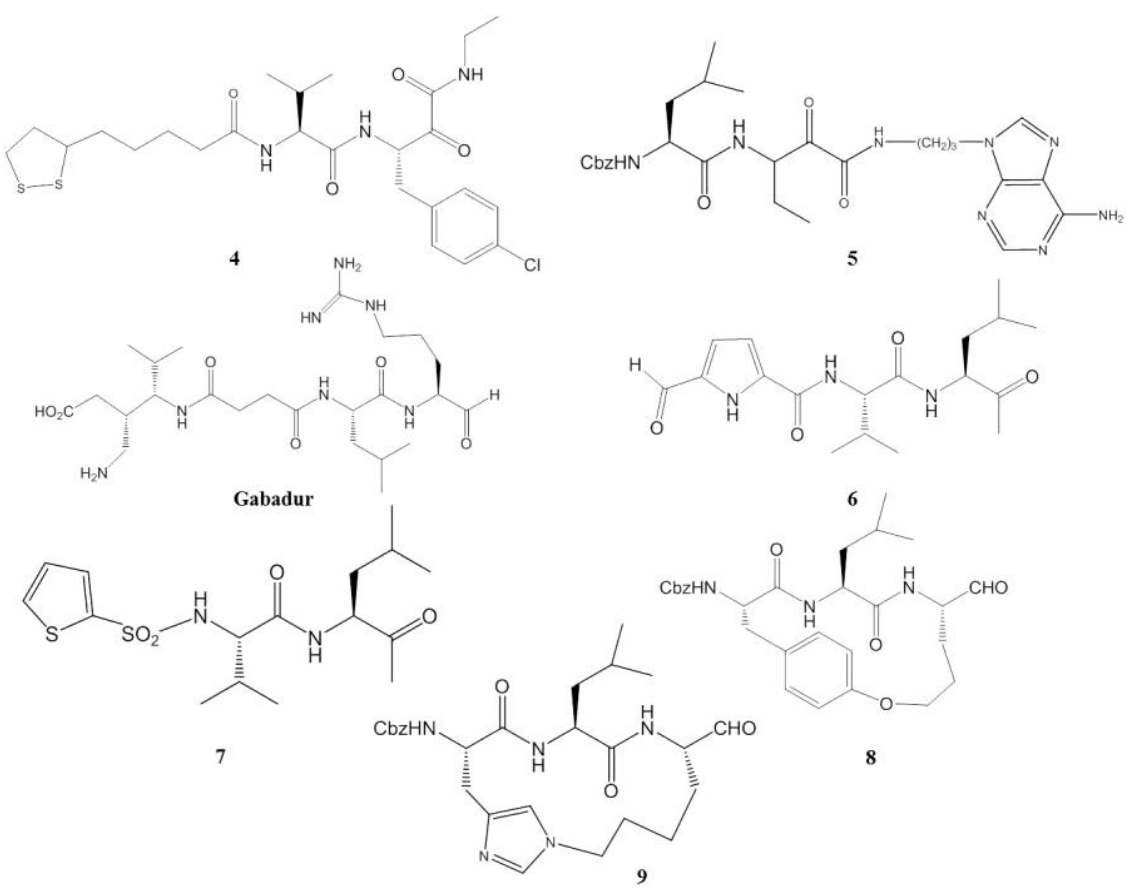

Figure 4 structure of substrate based peptide calpain inhibitors with BBB permability, isomer selectivity or $\beta$-strand geometry.

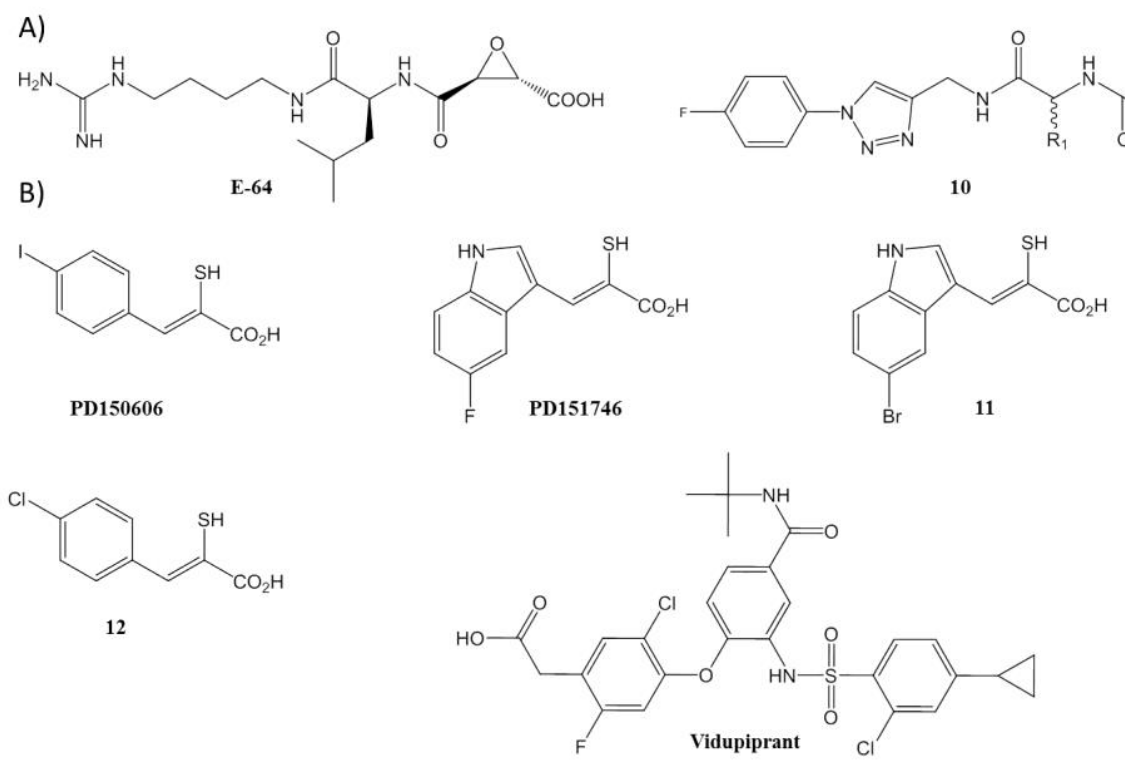

Figure 5 structure of A) inhibitos with epoxy group, and B) allosteric inhibitors. 